42nd AIAA Aerospace Sciences Meeting and Exhibit

Reno, Nevada

5-8 Jan. 2004

\title{
DEVELOPMENT AND TESTING OF A DROGUE PARACHUTE SYSTEM FOR X-37 ALTV / B-52H SEPARATION ${ }^{* * *}$
}

\author{
Stephen A. Whitmore, ${ }^{*}$ Brent R. Cobleigh ${ }^{\dagger}$ Steven R. Jacobson, ${ }^{\ddagger}$ and Steven C. Jensen ${ }^{\S}$ \\ NASA Dryden Flight Research Center \\ Edwards, California \\ Elsa J. Hennings ${ }^{\text {II }}$ \\ Naval Air Warfare Center \\ China Lake, CA
}

\begin{abstract}
NOMENCLATURE

Multiple scenarios were identified in which the X-37 approach and landing test vehicle (ALTV) catastrophically recontacts the B-52H carrier aircraft after separation. The most cost-effective recontact risk mitigation is the prelaunch deployment of a drogue parachute that is released after the X-37 ALTV has safely cleared the B-52H. After release, a fully-inflated drogue parachute takes $30 \mathrm{~min}$ to reach ground and results in a large footprint that excessively restricts the days available for flight. To reduce the footprint, a passive collapse mechanism consisting of an elastic reefing line attached to the parachute skirt was developed. At flight loads the elastic is stretched, allowing full parachute inflation. After release, drag loads drop dramatically and the elastic line contracts, reducing the frontal drag area. A 50 percent drag reduction results in an approximately 75 percent ground footprint reduction. Eleven individual parachute designs were evaluated at flight load dynamic pressures in the High Velocity Airflow System (HIVAS) at the Naval Air Warfare Center (NAWC), China Lake, California. Various options for the elastic reefing system were also evaluated at HIVAS. Two best parachute designs were selected from HIVAS to be carried forward to flight test. Detailed HIVAS test results are presented in this report.

Acronyms

ALTV approach and landing test vehicle

CPT control position transducer

DCTF Drogue Chute Test Fixture

DFRC Dryden Flight Research Center

HIVAS High Velocity Airflow System

JSC Johnson Space Center

NAWC Naval Air Warfare Center

RTD resistance thermal device

$\underline{\text { Symbols }}$

a performance index weight, 1.0

$A_{\text {base }} \quad$ drogue parachute fixture base area, $\mathrm{ft}^{2}$

$b$

performance index weight, 2.0

c performance index weight, 2.0

$C_{D} \quad$ drag coefficient

$C_{D} A \quad$ parachute drag area, $\mathrm{ft}^{2}$

$d$

performance index weight, subjective

*AIAA Associate Fellow, Aerospace Engineer

$d A$

incremental drag area, $\mathrm{ft}^{2}$

${ }^{\dagger}$ AIAA Senior Member, Aerospace Engineer.

¥AIAA Senior Member, Aerospace Engineer.

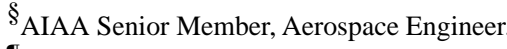

II AIAA Member, Crew Systems Engineer.

\#Note that use of trade names or names of manufacturers in this document does not constitute an official endorsement of such products or manufacturers, either expressed or implied, by the National Aeronautics and Space Administration.

${ }^{* *}$ This material is declared a work of the U.S. Government and is not subject to copyright protection in the United States.

$D$

J

J

$l$

$\bar{q}$

$r$

$u_{\min }$

drag force, lbf

performance index

length of riser and suspension lines, $\mathrm{ft}$

dynamic pressure, $\mathrm{lb} / \mathrm{ft}^{2}$

radial offset from wake center, $\mathrm{ft}$

minimum velocity within wake, $\mathrm{ft} / \mathrm{s}$




$\begin{array}{ll}V & \text { flow velocity, ft/s } \\ V_{e} & \begin{array}{c}\text { uniform flow velocity at edge of HIVAS } \\ \text { flow, } \mathrm{m} / \mathrm{sec} \mathrm{ft} / \mathrm{s}\end{array} \\ Y & \begin{array}{l}\text { lateral offset from centerline of HIVAS } \\ \text { nozzle, } \mathrm{ft}\end{array} \\ Z & \text { vertical offset from ground plane of } \\ & \text { HIVAS C-2 test pad, ft } \\ \Delta V & \text { drogue parachute test fixture wake velocity } \\ & \text { defect, m/sec } \\ \delta & \text { wake half width, ft } \\ \delta \theta & \text { pitch angle amplitude standard deviation, } \\ & \text { deg } \\ \delta \psi & \text { yaw angle amplitude standard deviation, } \\ & \text { deg } \\ \psi_{\text {mean }} & \text { total root-sum-square coning angle } \\ \delta_{\text {rss }} & \text { mean pitch angle, deg } \\ & \text { mensity, lbm/ft }\end{array}$

The X-37 vehicle was originally conceived as an integrated test bed to mature technologies critical to the advanced military space operations. The X-37 grew out of the X-40A program that teamed the Air Force with NASA and the Boeing Company (Chicago, Illinois), in a cooperative agreement to develop a small, highly-maneuverable, reusable spacecraft known as the "space maneuvering vehicle" (SMV). A series of X-40A flight tests was concluded at the NASA Dryden Flight Research Center (DFRC), Edwards, California, in the spring of 2001. The X-37 vehicle is a 120-percent scale version of the X-40A, with a length of $27.6 \mathrm{ft}$ and a wingspan of approximately $15 \mathrm{ft}$. Some of the X-40A outer mold lines have been modified to provide better hypersonic and supersonic performance and flying qualities. The Boeing Phantom Works division in Palmdale, California is currently working on two X-37 vehicles. Vehicle 1, dubbed the "approach and landing test vehicle" (ALTV), will be used for a series of atmospheric flight tests to evaluate the subsonic flight characteristics, and to validate the guidance, navigation, and control systems and algorithms used for landing the spacecraft. The second X-37, dubbed the "orbital vehicle" (OV), will be "spaceworthy" and is currently envisioned for at least one orbital flight and possibly more. Results of the approach and landing flight tests will be used to validate vehicle hardware and refine energy management techniques used in return-from-orbit operations. Atmospheric flight tests will be conducted at DFRC. Test plans for the ALTV call for carrying the vehicle aloft on the wing station of a B-52H-model bomber and releasing it at Mach 0.7 and an approximate altitude of $12.95 \mathrm{~km}(42,500 \mathrm{ft}$.) mean sea level. After release, the X-37 will glide to a horizontal landing. Figure 1 shows an artist's depiction of the X-37 ALTV soon after release from its pylon attachment under the right wing of the B-52H carrier aircraft. The X-37 vehicle development, both ALTV and $\mathrm{OV}$, is funded under a NASA contract managed by the NASA Marshall Space Flight Center (MSFC) in Huntsville, Alabama.

\section{ANALYSIS OF THE X-37 ALTV / B-52H SEPARATION EVENT}

A primary NASA responsibility on the X-37 ALTV project is to ensure a safe, clean separation of the $\mathrm{X}-37$ ALTV from the B-52H. If a post-drop recontact between the $\mathrm{X}-37$ ALTV and $\mathrm{B}-52 \mathrm{H}$ were to occur, there is a high potential for significant damage including the loss of one or both vehicles. For most of the previous lifting body-reentry vehicle shapes dropped from the B-52, achieving a positive separation at launch was not especially difficult compared to the X-37 ALTV. The X-37 ALTV, like the Space Shuttle, is not a lifting body, but instead has a delta wing that produces considerable lift at subsonic speeds. At the drop Mach number (0.7) the vehicle has a maximum lift/drag ratio $\left(\mathrm{L} / \mathrm{D}_{\max }\right)$ that exceeds 4.4. When this comparatively high lift/drag ratio (L/D) is combined with the 7000-lb empty weight, the X-37 ALTV flies rather well compared to other lifting body configurations. By comparison, for its initial drop from the B-52B, the $\mathrm{X}-38 \mathrm{~V}-131 \mathrm{R}$ vehicle had an $\mathrm{L} / \mathrm{D}_{\max }$ of only 2.0 and a drop weight of 18,000 lb. ${ }^{1}$

Another possibly more significant complication for separation is that the X-37 ALTV control system is entirely autonomous and has no capability for pilot intervention in the event of off-nominal flight scenarios. The X-37 ALTV has oversized control surfaces designed for flight at hypersonic speeds and high angles of attack. These control surfaces have a large amount of excess control authority at subsonic speeds. If the autonomous control system of the X-37 ALTV commands the ruddervators to full maximum lift "hard over" during separation, the vehicle can generate sufficient lift to easily enable recontact with the tail or fuselage of the B-52H. The recontact hazard analysis was performed using a six-degree-of-freedom (DOF) real time, piloted simulation at DFRC. The piloted simulation approach was used for evaluating the 
recontact hazard in lieu of more traditional Monte Carlo batch simulations. In this analysis the X-37 was flown as a "hostile vehicle"; the simulation pilot flew the X-37 in a manner that actually attempted to force recontact between the X-37 and the B-52H. These piloted simulation techniques were pioneered in earlier programs at DFRC $^{2}$ and offer a distinct advantage because they allow a variety of candidate failure modes to be quickly analyzed and organized. Additionally, the piloted simulation technique allowed DFRC engineers to quickly evaluate the potential severity of a recontact event, which is paramount in this analysis. Figure 2 shows a simulation run with the $\mathrm{X}-37$ recontacting the B-52H tail area.

The X-37 ALTV test team classified the recontact scenario as a category 1-D hazard. This hazard classification presents a potential for "catastrophic consequences" (1) to the human-occupied B-52H, and was considered "unlikely but possible" (D). Based upon well-established NASA DFRC safety standards, this 1-D classification required, without some physical mitigations to prevent recontact, that the X-37 ALTV software be tested as class $\mathrm{A}-\mathrm{a}$ rating that is identical to software flying as an integral part of a human-occupied vehicle. Man-rating the flight control software would allow the recontact hazard to be carried as an accepted risk. However, requalification of the X-37 flight control software as class A was estimated as a multimillion dollar cost to the program and would delay the scheduled flight date by as much as two years. These programmatic impacts were considered unacceptable. Thus, physical mitigations to prevent recontact were required.

Several mitigations to the recontact hazard were investigated. These mitigations included locking out the control surfaces during launch, mounting the X-37 at negative angles of incidence on the pylon, limiting surface movement, rate-limiting actuators, prepositioning surfaces, blowing a cold jet to force separation, sliding the X-37 down four-foot guide rails at separation, carrying $1500 \mathrm{lb}$ ballast that could be ejected, and a deploying a drogue parachute during separation. Most options showed initial promise, however, all but one fell prey to operational or cost issues. The only solution that proved agreeable to all parties involved in the X-37 ALTV was to deploy a drogue parachute prior to separation. Due to uncertainty in the B-52H interference flow field shortly after drop and the experimental nature of the X-37 ALTV, the separation hazard analysis was performed in a conservative manner. For these analyses, 3- $\sigma$ "worst-on-worst" aerodynamic uncertainties that made recontact more likely, were used to perform the evaluation. The parachute drag coefficient and coning angles were varied over a wide range until it was determined that the recontact potential was eliminated to a 99.7 percent $(3-\sigma)$ confidence level. The drogue parachute will be deployed shortly before the launch of the X-37 ALTV, and be released approximately $2.8 \mathrm{sec}$ after launch. After release the drogue parachute, swivel, and attachment webbing will fall to the ground, leaving the X-37 ALTV free to fly a nominal approach trajectory. Figure 3 shows an artist's conception of the $\mathrm{X}-37$ and drogue parachute shortly after separation from the B-52H.

\section{X-37 DROGUE PARACHUTE DESIGN REQUIREMENTS}

The piloted simulation study concluded that a launch drag of at least $3300 \mathrm{lb}$ was necessary to eliminate recontact. At the ALTV drop conditions (Mach 0.7 and an altitude of $42,500 \mathrm{ft}$ ), the free-stream dynamic pressure $(\bar{q})$ is approximately $120 \mathrm{lb} / \mathrm{ft}^{2}$. Dividing the total drag force by dynamic pressure gives an approximate drag area, $C_{D} A$, of $27.5 \mathrm{ft}^{2}$. To allow for the momentum defect of the X-37 wake, the desired nominal drag area of the parachute was set at approximately 6 percent higher, or $29.12 \mathrm{ft}^{2}$. The X-37 ALTV is laterally and directionally unstable at subsonic speeds and when this natural vehicle instability is coupled with the aerodynamic interference field (downwash and sidewash) generated by the B-52H, large lateral forces generated by the drogue parachute have the potential to overwhelm the flight control system when the parachute coning angle in either the pitch or yaw axis became large enough. Conservative simulation studies by both NASA and Boeing set this stability limit at approximately $5 \mathrm{deg}$. Furthermore, these coning motions must occur within a frequency band that does not dynamically couple with the natural modes of the flight control system. Simulation studies conservatively set this coning frequency limit to be no less than $1.5 \mathrm{~Hz}$. Finally, the nominal time line for the X-37 ALTV drop tests requires the drogue parachute to be deployed for approximately $15 \mathrm{~min}$ prior to launch. However, under exceptional circumstances, such as an abort on a hot pass through the drop box, or in-flight troubleshooting of an actuator problem; the drogue parachute could be deployed for as long as 45 minutes. This long-duration exposure to high dynamic pressures (greater than $120 \mathrm{lb} / \mathrm{ft}^{2}$ ) mandated that the final parachute designs have a very high durability level.

The above parachute requirements are fairly stringent. There is no such thing as a generic parachute that will 
work for all situations. Parachutes are designed for particular flight envelopes based on speed, altitude, and required dynamic characteristics. Certain designs such as guide surface parachutes ${ }^{3}$ are specifically designed for high-Mach deployment and have good stability characteristics with low coning angles. Also, the solid form of these parachutes allows the canopy to be robustly constructed for high durability. However, guide surface designs typically have a relatively low drag coefficient-less than 0.30 - and would require a diameter of 12-15 $\mathrm{ft}$ to achieve the required drag force. This diameter is too large for the constrained space that was available behind the X-37 ALTV and under the B-52H wing. The required high stability can be achieved with other parachute designs such as highly porous conical ribbon parachutes. Conical ribbon designs have historically demonstrated good stability properties when deployed at high speeds. However, these parachute designs are typically fairly fragile and are not intended for long-duration deployments at high speeds. Thus, there was considerable risk that any particular design would not meet the requirements when deployed in flight.

\section{PARACHUTE DESIGNS TESTED}

Multiple candidate parachutes with varying design geometries were evaluated; nine new parachutes were constructed and two Space Shuttle main landing system pilot parachutes were modified and tested for this application. Seven of the parachutes were designed and fabricated by Syndex Incorporated (Torrance, California), a subcontractor to Boeing. The Crew Systems Division of the Naval Air Warfare Center (NAWC), China Lake, California, designed and fabricated two additional parachutes. The NASA Johnson Space Center (JSC), Houston, Texas supplied the Space Shuttle pilot parachutes to the X-37 ALTV program at no cost. The contractor-designed parachutes emphasized material strength as a means for meeting the long-term durability requirement mentioned earlier in this section. The NAWC parachute designs were based on the JSC-Space Shuttle pilot parachute design, but incrementally strengthened the horizontal ribbon material and the skirt-suspension line joints to ensure greater durability. All but one parachute design had a conical ribbon gore pattern, with the one remaining design using a conical ring-slot canopy pattern. All of the parachute designs used a 12-gore canopy pattern. A series of ground tests was used to select the two best designs. These designs will be carried forward to flight test on the B-52H to demonstrate airworthiness. The B-52H flights will be used to select a single design that will be used for the X-37 flight tests. Table 1 shows the matrix of parachutes that were evaluated during the X-37 drogue parachute ground tests. Key design features are listed. The data from the ground tests will be presented below in the "Results and Discussion" section.

Since substantial spinning can occur during the time that the parachute is deployed in the $\mathrm{X}-37$ / B-52H wake prior to launch and during the free flight, a roll-axis swivel is necessary between the $\mathrm{X}-37$ and the drogue parachute to keep the riser line from fouling. In the X-37 drogue parachute designs a single riser line was used to attach the parachute to the vehicle, and the swivel was mounted at the junction of the riser suspension lines.

Table 1. Parameter matrix for X-37 ALTV drogue parachute designs.

\begin{tabular}{ccccccc}
\hline \hline $\begin{array}{c}\text { Parachute } \\
\text { Name }\end{array}$ & $\begin{array}{c}\text { Diameter, } \\
\mathrm{ft}\end{array}$ & $\begin{array}{c}\text { Parachute } \\
\text { Type }\end{array}$ & $\begin{array}{c}\text { Canopy } \\
\text { Angle, deg }\end{array}$ & $\begin{array}{c}\text { Geometric } \\
\text { Porosity }\end{array}$ & $\begin{array}{c}C_{D} A, \\
\mathrm{ft}^{2}\end{array}$ & $\begin{array}{c}\text { Horizontal Ribbon } \\
\text { Strength, lb }\end{array}$ \\
\hline 1) Syndex 0a & 9.3 & Ribbon & 28 & $28.0 \%$ & 29.17 & $1500 \mathrm{lb}$ \\
2) Syndex 0b & 9.3 & Ribbon & 20 & $24.0 \%$ & 29.17 & $1500 \mathrm{lb}$ \\
3) Syndex 0c & 9.3 & Ring-Slot & 20 & $24.0 \%$ & 35.00 & $1500 \mathrm{lb}$ \\
4) JSC \#1 & 9.0 & Ribbon & 20 & $19.8 \%$ & 28.50 & $300 \mathrm{lb}$ \\
5) JSC \#2 & 9.0 & Ribbon & 20 & $19.8 \%$ & 28.50 & $300 \mathrm{lb}$ \\
6) NAWC \#1 & 9.0 & Ribbon & 20 & $19.8 \%$ & 28.50 & $460 \mathrm{lb}$ \\
7) NAWC \#2 & 9.0 & Ribbon & 20 & $19.8 \%$ & 28.50 & $550 \mathrm{lb}$ \\
8) Syndex \#1 & 9.5 & Ribbon & 20 & $19.8 \%$ & 29.17 & $300 \mathrm{lb}$ \\
9) Syndex \#2 & 9.5 & Ribbon & 20 & $22.0 \%$ & 29.17 & $460 \mathrm{lb}$ \\
10) Syndex \#3 & 9.5 & Ribbon & 20 & $24.0 \%$ & 29.17 & $460 \mathrm{lb}$ \\
11) Syndex \#4 & 8.5 & Ribbon & 20 & $24.0 \%$ & 28.50 & $1000 \mathrm{lb}$ \\
\hline \hline
\end{tabular}




\section{POST-RELEASE ELASTIC REEFING SYSTEM FOR DRAG AREA REDUCTION}

The addition of the drogue parachute to the X-37 presented additional problems with regard to flight operations. Due to the high launch altitude of the X-37 $(42,500 \mathrm{ft})$ the drogue parachute system will take nearly 30 min to reach the ground. In that amount of time, the winds aloft can cause the drogue system to land in a very large area, including several heavily traveled highways. Flight operations simulation studies have shown that during winter months the prevailing winds take the parachute off of the south border of the Edwards test range into civilian airspace a large percentage of the time. Since the drogue parachute release is a planned event and not an emergency or contingency operation, the Edwards Range Commander will not allow this range border violation. A predicted post-release wind drift footprint for a fully-inflated drogue parachute is shown in figure 4 . The limit lines show the landing footprints for the Edwards ${ }^{4}$ February mean, 1.0- $\sigma, 1.25-\sigma, 2.0-\sigma$, and 2.25- $\sigma$ winds. Both wind direction and magnitude are varied in these simulations. To a 99.7 percent confidence level, the prevailing winds take the drogue parachute off-range more than 45 percent of the time. This significant number of "no-fly" days has the potential to severely impact programmatic cost and schedule, and poses an unacceptable restriction to program operations. To prevent this occurrence, the X-37 ALTV team pursued means to reduce the parachute drag area after it has been released from the X-37 ALTV. Figure 5 shows the predicted February post-release wind drift footprint when the frontal drag area of the parachute has been reduced by 50 percent. The reduction of the footprint size is dramatic, and now predicted range violations occur for less than 5 percent of the available flight days.

Several methods to reduce the drag of the drogue parachute were examined, including release of half the risers-suspension lines, release of all the risers-suspension lines while attaching a line to the drogue vent to invert the parachute, as well as using an elastic cord attached to either the vent or used as a reefing line. Recall, as described earlier, the drogue parachute designs required that a swivel be used at the junction of the riser and suspension lines to ensure that the canopy would not foul during predrop operations. The anti-fouling swivel makes it difficult to implement the first two drag reduction methods, as the release would have to occur past the parachute swivel. Trade studies examined several more detailed electromechanical means to collapse the parachute. Each of these electromechanical solutions was considered too complex for operational feasibility, and eventually the X-37 team agreed on a simple "bungee cord" approach. The eventual design that was selected is very similar to conventional parachute reefing systems in which a short length of line routed through rings at the skirt of a parachute prevents the parachute from fully opening during a high-speed deployment. Typically this reefing is done to reduce the initial opening shock load. The reefing line is typically severed a few seconds after deployment, when the velocity has decayed, and the parachute then opens fully. In the X-37 ALTV drogue parachute design an elastic reefing line is used to replace the traditional reefing "hard line." When the parachute is deployed under full drag load, the elastic line is stretched and does not affect the drag. When the load is reduced, the elastic contracts, the frontal area of the parachute is reduced, and the total drag drops. Figure 6 illustrates this concept. This simple drag reduction concept is completely passive, self-regulating, and easily integrated with the X-37 drogue parachute design.

However, there were several factors complicating the application of this simple concept. Most significantly, the drogue parachute will be thoroughly cold-soaked during the time required to climb to altitude and during preparation for X-37 launch. Typical midlatitude temperatures at the launch altitude of the X-37 $\left(42,500 \mathrm{ft}\right.$.) approach $-65^{\circ} \mathrm{F}$, and very few materials can remain elastic at such extreme cold temperatures.

Literature searches and consultations with chemical manufacturers eventually identified a commercially available product that had the potential to work for this application. The elastomer is typically used as a low-temperature encapsulant for spacecraft electronics, and no database for tensile force applications was available. In fact, the manufacturer had never stress-tested the material at low temperatures to develop tensile stress/strain curves. Clearly, this data is essential in order to determine the size and elongation of the elastic cord required to develop a balance between the full drag load and released load conditions. With too large a tensile force on the "bungee" the parachute will not inflate fully under flight load; with too small a tensile force the drag area will not be sufficiently reduced. Thus, significant development work was conducted in order to verify that the elastomer was sufficient for this application, and to tune the size of cord cross section. Once the preliminary elastomer reefing system concepts were designed and fabricated, these systems were evaluated for performance during the ground tests that were used to characterize the performance of the candidate parachute designs. These tests were used to further refine the design of the reefing 
system concept. The experimental setup and procedures used for the X-37 drogue parachute ground tests will be described in detail in the following section.

\section{AERODYNAMIC GROUND TESTING OF THE DROGUE PARACHUTE SYSTEMS}

Because highly porous parachute designs (required for coning stability) have performance characteristics that vary significantly with the dynamic pressure loads exerted on them, a low-speed test is insufficient to allow proper characterization of parachute performance. Similarly, these parachutes do not scale well to smaller sizes and lower Reynolds numbers, and a full-scale test is required to get a proper certification. With the NASA Ames Research Center (ARC) $40 \times 80 \mathrm{ft}$ wind tunnel currently being prepared for closure, only one American facility was available that could allow for full-scale testing at flight dynamic pressure loads in the time frame required by the X-37 program. That facility is the High Velocity Airflow System (HIVAS) at the NAWC. The HIVAS is a facility of the NAWC Weapons Survivability Laboratory (WSL). The WSL provides the Navy and the Department of Defense with the unique capability to conduct ballistic tests with a broad spectrum of threat munitions ranging from small arms to full missile warheads. The bypass airflow from four TF-33 P11 turbofan engines ducted to single or dual nozzles provides the HIVAS flow. HIVAS airflow simulating localized in-flight conditions with a nozzle exit core velocity as high as $500 \mathrm{kn}$ can be provided. The goal of the HIVAS tests was to certify two parachute designs and bring these designs forward for flight testing. The flight tests would ultimately allow the X-37 program to down-select to a single parachute design for flight tests.

The original HIVAS test plan called for three drogue parachute candidates to be tested at full-scale dynamic pressures $\left(120 \mathrm{lb} / \mathrm{ft}^{2}\right)$ in the HIVAS flow field. In order to maximize the flow field similarity to the actual flight environment, an X-37-like fuselage and body flap model was located in the flow field. This full-scale model dubbed the "drogue chute test fixture" (DCTF) housed instrumentation to measure the parachute load and dynamics. As will be described in detail in the "Results and Discussion" section, with the X-37 DCTF in the flow field the achieved dynamic pressure levels in the vicinity of the parachute skirt were significantly lower than the required flight level even with all four engines operating at 100 percent thrust. It was speculated that the DCTF blocked enough of the core nozzle flow that the dynamic pressure was reduced dramatically. Full flight load dynamic pressures (approximately $120 \mathrm{lb} / \mathrm{ft}^{2}$ ) could not be achieved with the DCTF in the flow. These flight load levels were considered essential to characterizing the high-speed dynamics and drag characteristics of the candidate parachutes. Thus it was determined that the X-37 DCTF model should be removed in order to achieve full flight load dynamics pressures, and a second phase of testing was performed. During the second phase of testing at the HIVAS facility, with the DCTF removed, full flight load dynamic pressures were easily achieved. Three parachutes were tested: the two best designs from the Phase I tests and one parachute originally designed for the Space Shuttle as a pilot for the main landing parachute and supplied by JSC. In the Phase II tests both of the original drogue parachute designs had unacceptable high-speed characteristics. When the JSC Space Shuttle pilot parachute was tested as an evaluation of the HIVAS flow effects, the parachute inflated well and was extremely stable. While it is possible that either the weights of the canopies or the airflow pattern of the HIVAS system could have contributed to the inflation problems of the original parachutes, the extreme differences between their performance and the JSC Space Shuttle pilot parachute point to problems with the original designs. A third set of HIVAS tests was clearly required. The Phase III HIVAS tests revisited the original designs tested during the Phase I and Phase II tests. For the Phase III HIVAS a total of eight parachute designs were tested. As with the Phase II tests, the DCTF was removed from the flow field and only the parachute-riser combination was tested. Each of these tests phases will be described in detail in the following three subsections.

\section{Phase I HIVAS Test Setup}

The goal of the initial phase of testing at the HIVAS facility was to down-select to two candidate drogue parachutes (from a total of three). A successful parachute design would meet the following criteria:

1. Ability to properly inflate at flight dynamic pressure level

2. Coning angles $<5 \mathrm{deg}$

3. Drag area $\left(C_{D} A\right) \sim 2.71 \mathrm{~m}^{2}\left(29 \mathrm{ft}^{2}\right)$

4. Distinct parachute coning frequencies $>1.5 \mathrm{~Hz}$

5. Survive functionally intact for $45 \mathrm{~min}$ at flight dynamic pressure

6. Beyond 45 min cumulative exposure to flight $\bar{q}$, the parachute must not fail in a manner that presents a danger to either the $\mathrm{X}-37$ or B-52H; i.e. no shedding of "hard" parts, swivel, connectors, etc. 
As mentioned earlier, for these tests the X-37 DCTF model was mounted in the HIVAS flow field. The roughly full-scale DCTF model consists of a cylindrical top, vertical sides, and flat bottom matching the basic X-37 dimensions. The DCTF includes a simulated body flap mounted at the aft end and deflected down $16 \mathrm{deg}$ from the body centerline. This flap position simulates the launch position of the X-37 body flap. The test fixture has a faired elliptical nose approximating the X-37 ALTV nosecone. The fixture-housed pallet held mounted instrumentation to measure the parachute loads, inflation stability, dynamic pressure in the flow field, and parachute coning angle dynamics. Figure 7 shows the DCTF mounted in the HIVAS facility. Test measurements were recorded by a self-contained instrumentation system designed and built by NASA specifically for the HIVAS tests. The heart of the instrumentation system is the National Instruments (Austin, Texas) Compact Fieldpoint ${ }^{\circledR}$-a modular, distributed input/output (I/O) system that uses a 100 MBS Ethernet bus to manage all instructions and data flow. A laptop computer located in an instrumentation bunker was used to manage all data flow to and from the instrumentation system. Graphical displays on the laptop provided a variety of real time diagnostics data. Data from each test run was also logged and stored on the laptop for additional post-test analyses. Figure 8 shows the HIVAS Fieldpoint ${ }^{\circledR}$ assembly and measurement sensors mounted to the instrumentation pallet.

The primary instrumentation fixture was a three-DOF custom-designed balance that allowed the parachute position in the flow field and the axial load on the parachute riser to be measured in real time. The balance was designed to pivot in the pitch and yaw axis and allows the forces acting on the load cell to always remain in tension. Roll-induced moments and forces on the parachute riser were relieved by the swivel attachment at the downstream end of the parachute riser. Figure 9 depicts the load balance and its mounting in at the aft end of the test fixture. In order to characterize the parachute loads and dynamics a variety of sensors were mounted on the swivel arm of the test balance. These sensors include three-axis rate gyros, a three-axis linear accelerometer, pitch and yaw angle control position transducers (CPTs), and a strain gage load cell. The rate gyro and accelerometer sensors were integrated into a single "gyro and accelerometer package" that managed the analog signal outputs along a single cable. The dynamic sensor information was blended using Kalman sensor fusion techniques ${ }^{6}$ to reduce vibration contamination and add fidelity. The resulting filtered time history estimates give the parachute load, position, angular, and linear velocities. Figure 9 also shows how the individual sensors were mounted on the load balance.

Previous testing at HIVAS has shown that the flow field is nonuniform across any given cross section and also varies as a function of distance aft from the HIVAS nozzle exit plane. This flow field nonuniformity means the drogue parachute experiences a different "effective" dynamic pressure, depending on its position within the flow field. These variations must be accounted for when calculating the parachute drag coefficients from the raw force measurements. To capture this measurement, a pitot tube, mounted on the parachute riser line, was designed for the HIVAS tests. The pressure signal from the pitot tube was transmitted to a pressure transducer mounted on the instrumentation pallet via a length of Viaton ${ }^{\circledR}$ (Viaton Industries Limited, Matlock, United Kingdom) tubing sewn to the length of the parachute riser. This pitot tube is shown mounted to the riser line in figure 10. Ambient pressure was obtained by routing a length of Viaton ${ }^{\circledR}$ tubing from the instrumentation pallet, well outside the HIVAS flow field. Pneumatic lags on the pitot measurement were measured to be less than $0.07 \mathrm{sec}$, and were considered acceptable. Local ambient temperature was sensed by a resistance thermal device (RTD) sensor mounted on the base area of the test fixture. The sensed pressure and temperature measurements allowed the local dynamic pressure, Mach number, and flow velocity to be computed and displayed in real time.

\section{Phase II HIVAS Test Setup}

During the initial HIVAS testing phase, pressure surveys with the X-37 DCTF in the flow field as well as pitot pressures sensed by the in situ pitot probe clearly indicated that the achieved dynamic pressure levels in the vicinity of the parachute skirt were only 40-60 percent of the required flight level even with all four HIVAS engines operating at 100 percent thrust. It was speculated that the X-37 DCTF model blocked enough of the core nozzle flow that the dynamic pressure was reduced dramatically. Also, because of its body length, the X-37 DCTF when combined with the length of the parachute riser and suspension lines, placed the parachute $100 \mathrm{ft}$ aft of the nozzle exit plane. This far aft in the flow field, the HIVAS-generated dynamic pressure begins to drop off rapidly. Because of the high levels of porosity of the X-37 drogue parachutes, it was critical that the parachutes be characterized at full flight load dynamic pressure levels. Porous parachute designs can often have good low-speed inflation and coning angle characteristics but perform poorly at high speeds. As will be shown in the 
"Results and Discussion" section, this was exactly what occurred during the HIVAS parachute tests. Also, for endurance testing, it was essential to demonstrate that the parachutes would survive at full flight loads. Thus, a second set of tests with the X-37 DCTF model removed from the HIVAS test pad, dubbed Phase II, were required. For the Phase II tests, the three-DOF force balance and instrumentation pallet was adapted to be mounted in the flow field without the X-37 DCTF. The force balance was mounted on a pole in the flow field at a point where full flight load dynamic pressure levels could be easily achieved, and the instrumentation pallet was mounted under the HIVAS nozzle, out of the flow field. Figure 11 shows a candidate drogue parachute positioned in front of the HIVAS nozzle, mounted to the test fixture, and ready for testing. In this series of tests, the parachute was positioned a bit above the nozzle centerline to account for sag in the riser line due to parachute weight. This position bias was determined visually (by trial and error) and allowed the parachute to be nominally centered in the HIVAS flow when fully inflated.

As was described earlier, the day of flight operations for the $\mathrm{X}-37$ required that the drogue parachute be deployed prior to dropping the $\mathrm{X}-37$ from the $\mathrm{B}-52 \mathrm{H}$ carrier aircraft. This predrop deployment can be as long as $45 \mathrm{~min}$, and poses a real challenge to the parachute construction. During the Phase I and Phase II HIVAS tests, it was determined that the original parachute designs had generally unacceptable performance. The designs exhibited a disturbing tendency to "squid" in the
HIVAS flow field; that is, the parachutes would overinflate and then deflate, rapidly and repeatedly. This lack of inflation stability exacerbated the coning angle instability. Originally, it was suspected that the HIVAS flow caused this problem, but a test conducted with a completely different design-the Space Shuttle pilot parachute supplied by JSC-demonstrated excellent coning angle and inflation stability. While it is possible that either the weights of the canopies, or the airflow pattern of the HIVAS system could have contributed to the inflation problems of the original parachutes, the extreme differences between their performance and the Space Shuttle pilot parachute point to design problems. A third set of HIVAS tests was clearly required.

\section{$\underline{\text { Phase III HIVAS Test Setup }}$}

A final set of tests, dubbed Phase III, was conducted at HIVAS with a much wider variety of parachute designs. In all, eight different parachutes were tested during Phase III at HIVAS. As with the earlier phases, the objective of the Phase III tests was to down-select to the two best designs to carry forward to flight. In the initial part of the Phase III tests, each of the parachutes was tested briefly (3-5 min) at flight dynamic pressure. Because a much wider array of parachutes was tested, a more objective criterion was needed to select the "best parachutes" to carry forward to flight test. An analytical metric was developed to allow the relative merits of the parachute designs to be compared. The metric incorporated the criteria listed in equation 1 into a single performance index, $\mathrm{J}$, where a smaller value indicates better performance;

i) Minimum deviation from ideal drag area

$$
\mathrm{J}=a \times\left[\frac{\left|\left(C_{D^{A}}\right)_{\text {mean }}-29.15 \mathrm{ft}^{2}\right|}{29.15 \mathrm{ft}^{2}}\right]+
$$

ii) Maximum lateral stability (minimum coning angle)

$b \times\left[\frac{\pi}{180}\left[\sqrt{\left.\frac{\left(\sum_{i=1}^{N}\left[\delta \theta_{i}-\theta_{\text {mean }}\right]^{2}\right)+\left(\sum_{i=1}^{N}\left[\delta \psi_{i}-\psi_{\text {mean }}\right]^{2}\right.}{N}\right)}\right]+\right.$

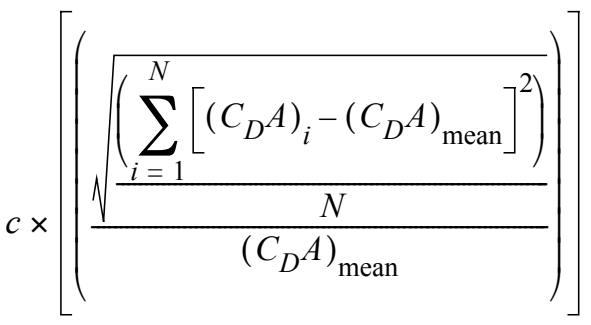

iii) Maximum inflation stability (constant drag area)

$$
+d(\text { subjective })
$$

iv) Maximum parachute durability 
The weights in equation $1\{a, b, c, d\}$ were chosen by the X-37 test team to be

$$
\begin{aligned}
& a=1.0 \\
& b=2.0 \\
& c=2.0
\end{aligned}
$$

and the final parameter, $d$, was reserved as a "tiebreaker." In other words, if two parachutes have the same value for $\mathbf{J}$ based on the first three criteria, then the parachute constructed of the heaviest material wins. Once the two best designs were selected, they would be taken forward to endurance testing. During the endurance tests, the parachutes were each exposed to flight dynamic pressure for a total of $45 \mathrm{~min}$, with the HIVAS facility being shut down at 15 -min intervals to allow for parachute inspection. The instrumentation system was basically identical for the Phase III testing except that the original load cell, a lightweight microelectronic mechanical system (MEMS) design, was replaced by a heavier more robust load cell design. It was feared that the original load cell would not survive the cumulative $90 \mathrm{~min}$ of endurance testing at full flight dynamic pressure. Small adaptations to the force balance were required to accommodate the heavier load cell.

\section{AERODYNAMIC FLIGHT TESTING OF THE DROGUE PARACHUTE SYSTEMS}

The two parachute designs down-selected from the HIVAS tests will be carried forward to flight test for final certification. The goal of the drogue parachute flight tests is to validate the deployment systems and aerodynamic performance in a representative flight environment and to select a single "best" parachute design for the actual ALTV flight test program. At least one flight is currently planned for each of the down-selected designs. The drogue parachute flight tests will use the X-37 DCTF model used in the Phase I HIVAS tests. The fixture mounts to the $\mathrm{B}-52 \mathrm{H}$ pylon in the same manner as the actual ALTV flight vehicle. This full scale model (the X-37 DCTF) will house instrumentation to measure the parachute loads and dynamics and a winch to vary the parachute riser length. The winch will allow movement of the drogue parachute over a 25-45-ft range, measured from the aft end of the test fixture to the parachute skirt. The drogue parachute will be stowed for flight within the $\mathrm{B}-52 \mathrm{H}$ pylon, and will be deployed from a pneumatically activated mortar tube installed in the pylon. The mortar tube design is identical to that which will be used for the actual X-37 flight tests and allows enough clearance to fire the drogue parachute into position behind the X-37 test fixture. The mortar tube installation does not inhibit the operation of the X-37 speed brake and minimizes the risk of the parachute becoming entangled with the X-37 ruddervators. The launch panel operator (LPO) operates the mortar pneumatic systems from inside the B-52H. Current plans call for the drogue parachute flights to be conducted in early 2004. The final parachute down-select should occur by early spring 2004 .

\section{RESULTS AND DISCUSSION}

This section describes the detailed results of the ground-based testing that was performed in order to eventually select the two drogue parachute designs taken forward to flight testing. Results of each of the HIVAS phases of testing will be presented first, and the detailed characteristics of the final two parachute designs will be presented. One major concern remaining after the three HIVAS phases is that the tests were not able to characterize the performance of the two final down-selected drogue parachutes at full flight $\bar{q}$ with the X-37 DCTF in the flow field. A brief argument is presented to demonstrate that the HIVAS tests without the DCTF were actually destabilizing when compared to a wake superimposed on a uniform flow field. Thus, the HIVAS tests are likely conservative when compared to the free-flight scenario. Finally, results of the testing performed to develop the elastic reefing system are presented. HIVAS test results that demonstrate the effectiveness of the design are shown.

\section{Phase I HIVAS Tests}

The three candidate parachutes that were evaluated during the initial testing at the HIVAS facility, were (as described earlier):

1. 9.3-ft diameter, $20^{\circ}$ cone angle, 24-percent porosity ribbon parachute

2. 9.3-ft diameter, $28^{\circ}$ cone angle, 28-percent porosity ribbon parachute

3. 8.5-ft diameter, 24-percent porosity ring-slot parachute

The parameter sets corresponding to these parachute designs are listed in items 1-3 in Table 1. The goal of the initial phase of testing at the HIVAS facility was to down-select to two candidate drogue parachutes (from a total of three). Initial testing concentrated on parachute characterization with the X-37 DCTF model in the flow field. All tests were performed on the HIVAS C-2 test pad using the 56-in. diameter round nozzle. Test runs were performed at 60 percent throttle setting and full throttle setting on each of the four engines. The 
60 percent setting gave a nozzle exit speed of approximately $300 \mathrm{kn}$ and the full throttle setting resulted in a nozzle exit speed of approximately $500 \mathrm{kn}$. These nozzle exit velocity values varied somewhat depending on the ambient temperature and pressure conditions. The 300-kn nozzle speed resulted in a dynamic pressure of approximately $41-52 \mathrm{lb} / \mathrm{ft}^{2}$ at the parachute skirt. The 500-kn nozzle speed resulted in a dynamic pressure of approximately $62-72 \mathrm{lb} / \mathrm{ft}^{2}$. Because HIVAS was not able to attain the flight dynamic pressure levels at the drogue parachute station with the X-37 DCTF in the flow field, quantitative results from the Phase I tests were not particularly useful. The primary use for these Phase I tests was to demonstrate the functionality of the instrumentation system under field conditions, and to learn how to use the facility itself. The HIVAS facility is not typically used for quantitative measurements, and there was a considerable learning curve that had to be negotiated.

A total of 21 runs were performed during the initial testing phase with the X-37 DCTF in place. The majority of the testing (17 runs) was performed with a riser length that positioned the parachute skirt $35.5 \mathrm{ft}$ aft of the model base. Each of the three candidate parachutes was also tested at the longest length of $48 \mathrm{ft}$ (three runs), with only the ring-slot parachute tested at the shortest distance of $25 \mathrm{ft}$ (one run). The one major quantitative result of the Phase I tests was that it quickly became apparent that the performance of the 28 percent ribbon parachute was completely unacceptable. This design never achieved full inflation at HIVAS and was quickly abandoned. The 24 percent ribbon parachute demonstrated adequate pitch and yaw stability characteristics at the 300-kn nozzle speed, but was marginal at the 500-kn nozzle speed. The original ring-slot parachute had good inflation characteristics but was highly unstable. Adding an additional $2.5 \mathrm{~cm}$ (1 in.) slot in the upper canopy near the vent modified this design in an attempt to increase the coning angle stability; the modified parachute, however, was only marginally more stable. When the modified parachute was permanently reefed to 73 percent of the nominal opening diameter, the stability was enhanced further. Unfortunately, even the final reefed configuration was near the ragged edge of meeting the coning angle requirements. Both the 24 percent ribbon parachute and the modified ring-slot parachute exhibited mean drag areas greater than the desired value of $29.12 \mathrm{ft}^{2}$. However, both parachutes demonstrated a disturbing tendency to squid. This characteristic would eventually disqualify all of the original parachute designs from flight test consideration and mandate that a completely new set of designs be developed,

\section{Phase II HIVAS Tests}

Because HIVAS could not achieve flight dynamic pressure levels with the X-37 DCTF in the flow field, the parachute properties under the full dynamic pressure loads were still not proven after the Phase I tests. Additionally, for endurance testing the parachutes needed to be loaded near the flight conditions to verify durability. Thus, for the follow-on tests the X-37 DCTF was removed from the pad and the 24 percent and modified ring-slot parachutes were evaluated at full $6000 \mathrm{p}\left(120 \mathrm{lb} / \mathrm{ft}^{2}\right)$ flight dynamic pressures. In this series of tests, the parachute was positioned so that it would be centered in the HIVAS flow when fully inflated. Using the airspeed sensed by the riser pitot tube, the HIVAS flow velocity was gradually increased from idle until the desired dynamic pressure level was achieved.

The results of the Phase II tests were both disappointing and conclusive. Both the 24 percent ribbon parachute and the modified ring-slot parachute had unacceptable high-speed drag and dynamic stability characteristics. While it is possible that either the heavy weights of the canopies or the airflow pattern of the HIVAS system could have contributed to the inflation problems, the propensity of the parachutes to squid points to design problems. The total porosity of the 24 percent ribbon parachute appears to be too high to allow for proper inflation and stability at the expected flight conditions. The fact that the parachute inflated well at lower speeds but would not open at higher speeds is indicative of excessive geometric porosity, excessive slot length, or a combination of both. The cause of the excessive geometric porosity appears to be that the ribbon material supplied to the subcontractor was narrower than anticipated, allowing more of a gap between ribbons than was designed. This actual ribbon width was not compensated for when the parachute was manufactured. The ring-slot parachute has similar problems. The stability of a round parachute is dominated by the porosity near the skirt, while the drag is more a function of the average porosity. Also, material weight and HIVAS airflow pattern may have been contributing factors in the erratic performance of the ring-slot design, as the parachute continued to partially inflate, fall out of the airflow, reinflate, and fall out of the airflow, repeatedly. When the porosity design flaw was combined with the heavy weight of the canopy and the unsettled nature and turbulence of the HIVAS flow field, the ring-slot parachute design unfortunately was unable to properly inflate and remain stable. 
When the Space Shuttle pilot parachute was tested as an evaluation of the HIVAS flow field characteristics, it inflated completely and was extremely stable in the flow field. It exhibited almost none of the inflation/deflation squid tendency shown by the other subcontractor designs. Figures 12 and 13 present a side-by-side comparison of the 24 percent ribbon, ring-slot, and JSC Space Shuttle pilot parachute. For these runs the approximate dynamic pressure level is $70 \mathrm{lb} / \mathrm{ft}^{2}$, a pressure level where all three parachutes achieved at least some level of inflation and remained somewhat stable in the flow field. The comparison plots display the absolute load of the parachute and the drag area calculated by dividing dynamic pressure into measured load on a point-by-point basis, and filtering the result. The drag area for the ring-slot parachute has a wide variability because the parachute continually inflates, deflates, and reinflates. In several instances the ring-slot parachute completely collapsed and fell out of the HIVAS flow field, causing the axial load to go to zero. The 24 percent ribbon parachute also shows a high level of variability in axial load, although the inflation/deflation/re-inflation cycle is not as pronounced as with the ring-slot parachute. Most importantly, as can be seen in figure 12 by the lower peak drag load, the 24 percent ribbon parachute never fully inflated. In contrast the Space Shuttle pilot parachute inflated completely and was very stable. It never experienced the inflation/deflation/reinflation cycle demonstrated by the other parachute designs. The computed drag area is essentially constant. The Space Shuttle pilot parachute appeared to have the correct amount of porosity, allowing it to inflate easily and remain extremely stable across a wide range of dynamic pressures. Figure 14 shows photographs taken of the three parachutes as they appeared during the HIVAS Phase III tests. The characteristics described above are readily apparent in these photographs, and the visual differences are striking. Only the Space Shuttle pilot parachute shows proper inflation characteristics. A third set of HIVAS tests was clearly required in order to understand and correct the extreme differences in performance between the Space Shuttle pilot parachute and the original subcontractor designs.

\section{$\underline{\text { Phase III HIVAS Tests }}$}

The parachute designs tested during HIVAS Phase III were modified to overcome the shortcomings discovered during the Phase I and Phase II tests. For the Phase III HIVAS a total of eight parachute designs were tested. These designs included: 1) two JSC-supplied Space Shuttle pilot parachutes, reefed for different drag areas to asses the effect on stability; 2) two enhanced-durability JSC Space Shuttle pilot parachute "clones" designed and fabricated by NAWC; and 3) four revised ribbon parachute designs fabricated by the original subcontractor. Phase II test results indicated that the JSC Space Shuttle pilot parachute design appears to have correct porosity, allowing for proper inflation and stability across a range of dynamic pressures. The NAWC designs reproduced the characteristics of the JSC Space Shuttle pilot parachute closely, with only the strength of the horizontal ribbon material being modified. The new Syndex designs differ significantly from the JSC Space Shuttle pilot parachute design, and offer a wider variation in layout geometries. Each of the eight parachute designs was tested briefly (2-4 $\mathrm{min}$ ) to determine the aerodynamic and stability properties and the two "best" parachutes were selected for endurance testing. The "J" metric discussed earlier was used to determine the down-selected parachute designs. The parameter sets corresponding to the parachute designs tested during Phase III are listed in items $4-11$ in Table 1.

The initial portion of Phase III testing was dedicated to characterizing the performance of each of the new parachute designs. During these tests each of the parachutes was tested at full flight dynamic pressure for 3-5 min. The parachute data were analyzed, and a "score" based on the performance index of equation 1 was computed. During these runs, the parachute was positioned in the flow field such that the skirt was approximately $33 \mathrm{ft}$ aft of the HIVAS nozzle exit. The distance from the force balance pivot point to the parachute skirt was approximately $23 \mathrm{ft}$. The resulting riser length from the balance pivot point to the junction of the suspension lines was $12.5 \mathrm{ft}$. This riser length was shorter than the nominal riser length $(25 \mathrm{ft})$ tested during the Phase I and II tests. This shorter length was chosen because it allowed the full flight dynamic pressure to be achieved at a lower HIVAS throttle setting of approximately 55 percent. The reduced throttle setting resulted in a considerable savings in fuel consumption and a per-minute reduction in operating costs. This cost savings was considered essential when the final two designs were endurance-tested for $45 \mathrm{~min}$ each.

Table 2 summarizes the results of the parachute evaluation tests. All of the parachutes except NAWC \#2 meet the coning angle criterion; Syndex \#3 displayed the greatest degree of stability and had the lowest (best) overall performance metric $(\mathrm{J}=0.167)$. The differences in the performances of the Syndex \#1 parachute $(\mathrm{J}=0.214)$ and the NAWC \#1 $(\mathrm{J}=0.219)$ were considered to be statistically insignificant. Because the 
NAWC \#1 parachute is a heavier ribbon design (\#460 MIL-T5608) than the Syndex \#1 parachute (\#330 MIL-T5608) design ${ }^{4}$, the test team decided in favor of the more sturdily constructed NAWC \#1 as the second down-selected parachute. Selection of the NAWC \#1 parachute as the second parachute also offers the advantage of having two distinctly different designs available for endurance and flight testing. The down-selected drogue parachutes met all of the minimum requirements described earlier.

Endurance tests exposed each of the down-selected parachute designs to full flight load dynamic pressures for a cumulative run time exceeding $45 \mathrm{~min}$. During the tests, the HIVAS was shut down at 15-min intervals to allow visual inspection for incipient damage to the parachutes. Table 3 shows a cumulative run time summary for each of the individual parachutes tested during HIVAS Phase III. The two down-selected parachutes were tested beyond the 45-min limits, and both canopies survived functionally intact with only superficial damage. Significantly, the swivel and riser attachment hardware (potential hard points whose in-flight failure could present a hazard to either the $\mathrm{B}-52 \mathrm{H}$ or the $\mathrm{X}-37$ ) were tested for a cumulative run time exceeding $140 \mathrm{~min}$. This exposure is at least 25 percent greater than what is expected in flight under even the most extreme emergency and return-to-base flight scenarios. Clearly, the lessons of the HIVAS Phase I and II tests were well-learned, and a successful set of parachute designs emerged from the Phase III testing.

Table 2. Parachute evaluation and down-select data summary.

\begin{tabular}{lcccccccc}
\hline \hline $\begin{array}{c}\text { Parachute } \\
\text { Name }\end{array}$ & $\begin{array}{c}C_{D} A \\
\mathrm{ft}^{2}\end{array}$ & $\begin{array}{c}\delta \theta \\
\mathrm{deg}\end{array}$ & $\begin{array}{c}\delta \psi \\
\mathrm{deg}\end{array}$ & $\begin{array}{c}\delta_{r S S} \\
\mathrm{deg}\end{array}$ & $\mathrm{J}$ & $\begin{array}{c}\text { Parachute } \\
\text { Dia., ft }\end{array}$ & $\begin{array}{c}\text { Reef } \\
\text { Dia., } \\
\mathrm{ft}\end{array}$ & $\begin{array}{c}\text { Dominant } \\
\text { Frequency, Hz }\end{array}$ \\
\hline JSC \#1 & 27.49 & 0.84 & 1.54 & 1.75 & 0.222 & 9.00 & 4.62 & $2.5-3$ \\
JSC \#2 & 27.08 & 1.29 & 1.57 & 2.03 & 0.240 & 9.00 & 4.62 & $2.5-3$ \\
NAWC \#1 & 28.05 & 1.40 & 2.14 & 2.56 & 0.219 & 9.00 & 4.62 & $2.5-3$ \\
NAWC \#2 & 28.69 & 3.51 & 6.10 & 7.04 & 1.033 & 9.00 & 4.62 & $2.5-3$ \\
Syndex \#1 & 29.72 & 0.95 & 1.59 & 1.85 & 0.214 & 9.50 & 9.50 & $3-3.5$ \\
Syndex \#3 & 30.15 & 1.01 & 1.14 & 1.52 & 0.167 & 9.50 & 9.50 & $3-3.5$ \\
Syndex \#2 & 31.15 & 1.12 & 1.18 & 1.63 & 0.266 & 9.50 & 9.50 & $3-3.5$ \\
Syndex \#4 & 26.66 & 1.15 & 1.74 & 2.09 & 0.253 & 8.50 & 8.50 & $3-3.5$ \\
\hline \hline
\end{tabular}

Table 3. HIVAS Phase III drogue parachute cumulative run time summary.

\begin{tabular}{lcc}
\hline \hline \multicolumn{1}{c}{ Parachute } & Parachute \# & $\begin{array}{c}\text { Run Time Min, } \\
\text { Cumulative }\end{array}$ \\
\hline Original JSC Pilot 1 & 0 & 17.050 \\
Original JSC Pilot 2 & 1 & 17.983 \\
NAWC Parachute \#1 & 2 & 47.500 \\
NAWC Parachute \#2 & 3 & 2.567 \\
Syndex Parachute \#1 & 4 & 2.017 \\
Syndex Parachute \#2 & 5 & 1.967 \\
Syndex Parachute \#3 & 6 & 48.900 \\
Syndex Parachute \#4 & 7 & 2.350 \\
& & total run time, min \\
& & 140.33 \\
\hline \hline
\end{tabular}




\section{HIVAS Effects on Parachute Stability}

As mentioned at the beginning of this section, one major concern with regard to the HIVAS tests was the inability to characterize the behavior of the down-selected parachutes at full flight dynamic pressures with the X-37 DCTF model in the flow field. Since the HIVAS tests without the DCTF in the flow field were ultimately used to down-select the two designs that will be carried forward to flight tests, it is critical to understand the effects of ignoring the X-37 DCTF. This subsection will offer evidence that the HIVAS flow was actually destabilizing to the parachutes and, when compared to the free-flight scenario, HIVAS represents a conservative test set. Thus, moving forward to flight test is a low-risk step. Figure 15 depicts the results of HIVAS flow field pitot-static surveys measured $30 \mathrm{~m}$ aft of the nozzle exit plane at 100 percent throttle setting for all four engines. Figure 15(a) plots the flow distribution without the DCTF model in the flow field, and 15(b) plots the velocity distribution with the DCTF model in the flow field. In these three-dimensional plots the flow velocity is plotted along the vertical axis, and the vertical and lateral position are plotted along the horizontal axes. It is readily apparent that: 1) the natural HIVAS flow distribution without the DCTF model has a "cone shape" (that is, the velocity is highest near the center and drops off more or less symmetrically away from this central core); and 2) when the DCTF is added to the flow field, the velocity distribution becomes more evenly spread, with the peak velocity significantly reduced from the nominal flow field without the DCTF. Figure 16 shows the resulting velocity defect $30 \mathrm{~m}$ aft of the nozzle caused by the DCTF model wake. This wake velocity distribution is computed by subtracting the flow field data depicted in figure 15(b) from the flow field data depicted in figure 15(a). When the total momentum defect is integrated across the wake ${ }^{7}$, the resulting drag coefficient $\left(C_{D}\right)$ is approximately 0.35 . This $C_{D}$ is slightly higher than expected for a blunt-based body of this size and shape ${ }^{8}$; however, considering the DCTF attachment and support structures also present in the flow field, this larger $C_{D}$ is not surprising. Figure 17 compares the measured DCTF wake velocity distribution-averaged vertically across the flow field and normalized by the peak velocity-against a theoretical wake for an axis-symmetrical body with a $C_{D}$ of 0.35 . The theoretical wake uses a standard cosine velocity distribution law of the form:

$$
\frac{u(r)}{V_{e}}=\frac{1}{2}\left[\frac{u_{\min }}{V_{e}}\left[1+\cos \left(\pi \frac{r}{\delta}\right)\right]+\left[1-\cos \left(\pi \frac{r}{\delta}\right)\right]\right]
$$

In equation 2 the parameter $r$ is the radial offset from the center of the wake, $\delta$ is the wake half width, $u_{\min }$ is the minimum velocity within the wake, and $V_{e}$ is the free-stream velocity of the uniform external flow. The parameters of equation 2 are related to $C_{D}$ by integrating the momentum defect across the width of the wake:

$$
\begin{gathered}
{\left[C_{D}\right]_{\text {base }}=\frac{D}{\frac{1}{2} \rho V_{e}^{2} A_{\text {base }}}=\frac{2}{A_{\text {base }}} \int^{2 \pi}\left[\int_{D}^{\delta}\left[\frac{u(r)}{V_{e}}\left[1-\frac{u(r)}{V_{e}}\right]\right] r d r\right] d \theta=} \\
{\left[\frac{\pi \delta^{2}}{4 A_{\text {base }}}\right]\left[1-\frac{u_{\text {min }}}{V_{e}}\right]\left[1+\left[3-\frac{16}{\pi^{2}}\right] \frac{u_{\text {min }}}{V_{e}}\right]}
\end{gathered}
$$


The agreement between the measured and predicted velocity distributions is very good, and lends credibility to the assertion that the measured wake in the HIVAS flow field (figure 16) is representative of the wake that would occur if the DCTF forebody was placed in a uniform flow field. When the drogue parachute is placed in a nonuniform flow field, as with the HIVAS tests, both pitching and yawing moments are induced. These induced moments are

Pitching moment:

$$
M_{\theta}=-\int_{\begin{array}{c}
\text { chute } \\
\text { area }
\end{array}} d(D) \times 1 \sin (\theta) \cdot d A
$$

Yawing moment:

$$
M_{\psi}=-\int_{\substack{\text { chute } \\ \text { area }}} d(D) \times 1 \sin (\psi) \cdot d A
$$

The moments are induced by the variability in the incremental drag across the skirt opening

$$
d(D)=C_{D}^{\bar{q}} d A
$$

Equation 6 assumes that the drag effectiveness of the parachute is constant across the skirt, and that the variability in the local drag is a result of the variable distribution of dynamic pressure. The induced pitching moment can be numerically evaluated for the HIVAS flow field by numerically integrating across the width of the skirt. The drogue parachute pitching moments induced by the nonuniform cross section of the HIVAS flow field are plotted as a function of pitch angle in figure 18. These moments are computed using the flow field survey data obtained $30 \mathrm{~m}$ aft of the nozzle exit plane. Also plotted in figure 18 is the induced pitching moment resulting from the wake data of figure 16 superimposed on a uniform flow equal in velocity to the mean HIVAS flow on the lateral centerline $30 \mathrm{~m}$ aft of the nozzle. Several features stand out in this figure: 1) the HIVAS flow conditions, both with and without the DCTF, tend to be destabilizing with regard to the induced pitching moment. That is, near the centerline of the flow and increasing pitch angle results in a growing pitching moment; 2) the DCTF wake tends to have a stabilizing effect. That is,

$$
\frac{\partial M_{\theta}}{\partial \theta}<0
$$

and increasing pitch angle results in a decreasing pitching moment; and finally, 3) near the centerline of the flow field, the slope of the pitching-moment curve is less severe for the data with the DCTF in HIVAS than without the DCTF. Thus, the flow field is more stable with the DCTF present. Figure 19 presents similar results for the yaw axis. The effects are even more pronounced. Also of interest to note in figures 18 and 19 is that the HIVAS-induced pitching and yawing moments have "flat spots" near the edges of the flow field. These predicted neutral-stability spots were also empirically observed to exist in the flow field. During the HIVAS tests, the parachutes would periodically "jump out" of the core flow and become stabilized near the outer edge of the flow field. The HIVAS operator overcame this nuisance phenomenon by throttling back on the nozzle speed until the parachute repositioned into the core flow field. This process of catching the parachute before it lifted out of the core flow field was described as being akin to "flying a kite."

The main point to "take away" from figures 18 and 19 is that the presence of the DCTF in the flow field has a stabilizing influence. The ramification of this result is quite significant. The HIVAS "cone flow" tends to be destabilizing as compared to uniform free-stream flow, and the tendency is for the parachute to "fall away from the center." Conversely, the effect of the DCTF wake is actually stabilizing and the parachute tends to "fall to the center." Consequently, it can be concluded that the HIVAS without the X-37 DCTF tests were a conservative certification of the parachute stability when compared to the free-flight environment, which is analogous to a wake superimposed on a uniform flow. Thus, the inability of HIVAS to achieve full flight dynamic pressures with the DCTF model in the flow field is not a limitation on the HIVAS tests.

\section{Development and Testing of the Elastic Reefing System}

As mentioned earlier, if the drogue parachute remains fully inflated after being cut loose from the X-37, prevailing local winds blow the drogue parachute off-range a significant portion of the time, and the resulting high number of "no-fly" days poses an unacceptable restriction to program operations. In order to prevent this occurrence, the X-37 team pursued the 
means to reduce the parachute drag area after release. The most promising solution involved a simple "bungee" system in which an elastic cord is affixed to the drogue skirt; when deployed under full drag load, the elastic line is stretched and does not affect the drag. When the load is reduced the elastic contracts, reducing the drag area of the parachute. The major potential "road block" to implementing this system is the inability of the elastic line to effectively operate at the predicted extremely low temperatures. Extensive research eventually identified a commercially available product with the potential to work for this application.

Multiple tests were conducted at DFRC and the China Lake NAWC to verify the suitability of the product for this application. In these tests the effectiveness of test "slugs" was evaluated against natural rubbers and other less exotic products. The samples were pulled to 100 percent elongation at room temperature, $-60{ }^{\circ} \mathrm{F}$ and $-90^{\circ} \mathrm{F}$. The $-60^{\circ} \mathrm{F}$ properties were nearly identical with the room temperature properties. At $-90{ }^{\circ} \mathrm{F}$ the elastomer is slightly stiffer and exhibits minor hysteresis. As the sample was warmed to $-60^{\circ} \mathrm{F}$, the hysteresis disappeared. Shock load tests were also performed. In general, the cold-temperature load characteristics of the samples were not practically different from the room-temperature load characteristics. Results of these tests convinced the $\mathrm{X}-37$ test team that the product was suitable for the reefing line application.

Several methods for fabricating the elastic cords were investigated, and eventually a satisfactory method for casting the lines as a single hoop was developed. The elastic silicone hoops were integrated into a working reefing system by encasing three 0.25 in. cross section thickness hoops in a single Teflon ${ }^{\circledR}$ (E. I. du Pont de Nemours and Company, Wilmington, Delaware) sleeve. The three individual elastic lines provided a level of redundancy in the event one or more lines would fail during drogue parachute deployment and flight operations. The Teflon ${ }^{\circledR}$ sleeve was attached to the drogue parachute by a series of $\operatorname{Kevlar}^{\circledR}$ (E. I. du Pont de Nemours and Company, Wilmington, Delaware) loops sewn to the parachute skirt. Figure 20 shows the elastomer reefing system as attached to the skirt of a test parachute.

During the Phase III HIVAS endurance tests, the elastic reefing system replaced the normal reefing hard line.

In order to evaluate the effectiveness of the elastomer reefing system, at the end of each test run the HIVAS nozzle speed was stepped downward until the system was at idle engine speed. Once stabilized at idle, the HIVAS was shut down completely, and as the engines spun down the deflation characteristics of the parachute were logged. This process would mimic the cycle that was expected when the drogue parachute was cut loose from the X-37. Figure 21 shows a typical parachute deflation cycle for a parachute without the elastomer reefing system. Figure 22 shows the same deflation cycle, but with the elastomer reefing system installed. In figure 21 (the parachute without the elastomer reefing system), notice that the total drag force drops proportionately with dynamic pressure, but that the drag area remains relatively constant throughout the shutdown process. Conversely, in figure 22 (the parachute with the elastomer reefing system), the drag area drops rapidly as the dynamic pressure drops below $35 \mathrm{lb} / \mathrm{ft}^{2}$. Clearly, the elastomer system is collapsing the parachute frontal area once the drag load drops low enough that the hoop forces on the skirt can no longer overcome the tensile forces of the elastomer bands. In addition, during the Phase III tests a total of nine parachute deflation cycles were obtained. The nine-run statistical average of the reefed drag area (when the reefing system had collapsed the parachute skirt) was approximately 42 percent of the unreefed drag area of the parachute. Clearly, the elastomer system was working as required and will be carried forward to flight testing.

\section{SUMMARY AND CONCLUDING REMARKS}

A primary NASA responsibility on the X-37 approach and landing test vehicle (ALTV) project is to ensure a safe, clean separation of the X-37 ALTV from the B-52H. The X-37 has some characteristics that make safe separation more difficult than that of previous lifting reentry configurations dropped from the B-52. Several mitigations to the recontact hazard were investigated. Operational or cost issues eliminated most options, and it was finally concluded that the drogue parachute solution is the most attractive option. This drogue parachute will be deployed shortly before the launch of the X-37, and be released from the X-37 after launch. After release, the drogue parachute and attachments fall to the ground, leaving the X-37 free to fly a nominal approach trajectory.

Because these parachute designs have drag and stability characteristics that vary significantly with the dynamic pressure loads exerted on them, a low-speed test is insufficient to allow proper characterization of the parachute performance. Thus, NASA selected the High Velocity Airflow System (HIVAS) to perform an initial 
high-speed characterization of the parachute properties. In early tests conducted at the HIVAS facility, the initial drogue parachute designs had unacceptable performance characteristics. When the Space Shuttle pilot parachute supplied by JSC was tested as an evaluation of the HIVAS flow effects, it inflated well and was extremely stable. While it is possible that either the weights of the canopies, or the airflow pattern of the HIVAS system could have contributed to the inflation problems of the original subcontractor-supplied parachutes, the large differences in performance point to problems with the original designs. A third set of HIVAS tests was clearly required. In the third and final phase of HIVAS testing a total of eight parachute designs were tested to select the best overall parachute designs. Endurance tests were performed on the two best designs and both parachutes survived intact for 45 min with only minor superficial damage. The two down-selected drogue parachutes will be flight tested in the B-52H flow environment to further refine the high-speed aerodynamic characteristics. The flight tests will allow NASA to down-select to a single configuration that satisfies all of the requirements for the ALTV flight tests.

Due to the high launch altitude of the X-37 $(42,500 \mathrm{ft})$, the drogue parachute system will take nearly $30 \mathrm{~min}$ to reach the ground. In that time, winds aloft can cause the drogue system to land in a very large area footprint. Flight operations simulation studies have shown that during winter months the prevailing winds take the parachute off of the south border of the Edwards test range into civilian airspace a large percentage of the time. This off-range event results in a significant number of "no-fly" days, and poses an unacceptable restriction to program operations. To prevent this occurrence, the X-37 team pursued means to reduce the parachute drag area after it has been cut loose from the X-37. A reduction of frontal drag area of 50 percent results in an approximately 75 percent reduction in the size of the impact area footprint. With this reduced footprint area-even under midwinter winds-aloft conditions-potential range violations occur for less than 5 percent of the available flight days.

The eventual design for this drag reduction system is similar to a conventional parachute reefing system. In this approach, however, an elastic line replaces the traditional reefing "hard line." When the parachute is deployed under full drag load, the elastic line is stretched and does not affect the drag. But when the load is reduced the elastic contracts, altering the drogue parachute shape and reducing the drag. This report concludes that the passive reefing system functions as designed, and with some modifications to ruggedize the system, is recommended for flight testing.

The final down-selected parachutes as tested in HIVAS were very stable with coning angles well under the required limits. Analysis demonstrates that the HIVAS cone flow tends to be destabilizing as compared to uniform free-stream flow. The result is that in the HIVAS tests the drogue parachute would tend to "fall away from the center." The effect of DCTF wake is actually stabilizing in terms of induced moments. The DCTF wake tends to cause the drogue parachute to "fall to the center." Thus the inability of HIVAS to achieve full flight dynamic pressures with the DCTF model in the flow field is not a limitation of the HIVAS tests.

The design challenges for the X-37 ALTV drogue parachute were significant. The program requirements for high-speed, long duration deployments of high drag, small diameter, high stability parachutes broke new ground. Parachute designs of this specific nature had never been constructed and tested. The unstable nature of the X-37 ALTV required that the parachute properties be very accurately characterized. Small changes in the parachute design features had dramatic effects on overall performance and durability. The lessons of the three phases of HIVAS testing were well-learned, and a successful set of parachute designs emerged that met all of the X-37 ALTV requirements. Current plans call for the drogue parachute flights to be conducted in early 2004. The final parachute down-select should occur by early spring 2004.

\section{REFERENCES}

${ }^{1}$ Saltzman, Edwin J., K. Charles Wang, and Kenneth W. Iliff, Aerodynamic Assessment of Flight-Determined Subsonic Lift and Drag Characteristics of Seven Lifting-Body and Wing-Body Reentry Vehicle Configurations, NASA/TP-2002-209032, 2002.

${ }^{2}$ Evans, M. B. and L. J. Schilling, The Role of Simulation in the Development and Flight Test of the HiMAT Vehicle, NASA-TM-84912, 1984.

${ }^{3}$ Knacke, T. W., Parachute Recovery Systems Design Manual, Para Publishing, Santa Barbara, CA, 1992.

${ }^{4}$ Range Reference Atmosphere Climatology, http:// www.edwards.af.mil/weather/rcc.htm Accessed December 9, 2003.

${ }^{5}$ Wolf, D. F. and R. H. Croll, "Wind-Tunnel Measurements of Dynamic Reefing Line Force in 
Ribbon Parachutes," AIAA 79-0465R, Journal of Aircraft, Vol. 18, No. 1, January 1981.

${ }^{6}$ Whitmore, Stephen A., Mike Fife, and Logan Brashear, Development of a Closed-Loop Strap Down Attitude System for an Ultrahigh Altitude Flight Experiment, NASA Technical Memorandum 4775, 1997.

${ }^{7}$ Whitmore, Stephen A., Stephanie Sprague, and Jonathan W. Naughton, Wind-Tunnel Investigations of Blunt-Body Drag Reduction Using Forebody Surface Roughness, NASA/TM-2001-210390, 2001.

${ }^{8}$ Hoerner, Sighard F., Fluid-Dynamic Drag: Practical Information on Aerodynamic Drag and Hydrodynamic Resistance, Self-published work, Library of Congress Catalog Card Number 64-19666, Washington, D.C., 1965.

${ }^{9}$ Whitmore, Stephen A., Marco O. Hurtado, Jose Rivera, and Jonathan W. Naughton, A Real-Time Method for Estimating Viscous Forebody Drag Coefficients, NASA TM-2000-209015, 2000. 


\section{FIGURES}

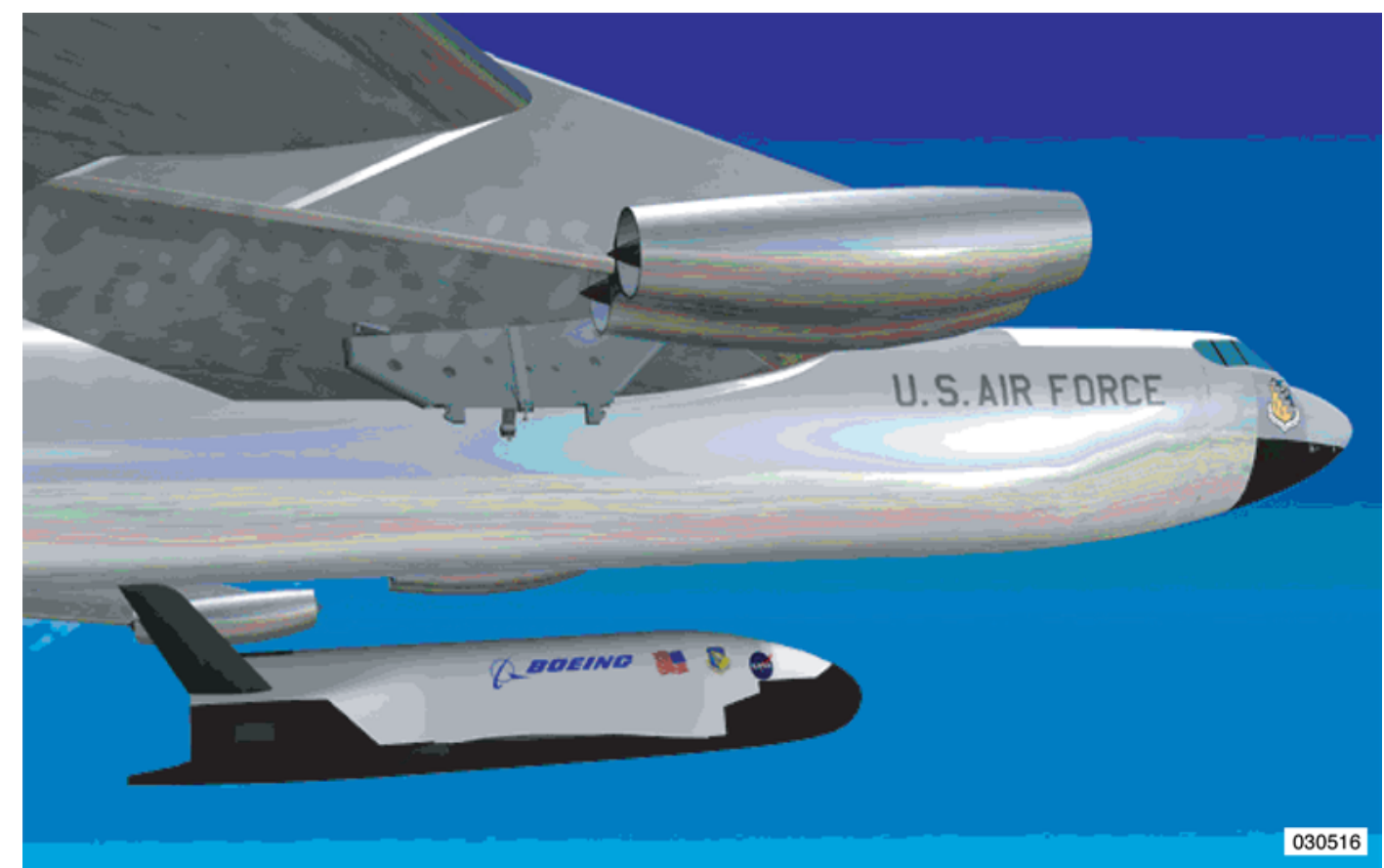

Figure 1. Artist's depiction of the X-37 ALTV after release from the B-52H pylon.

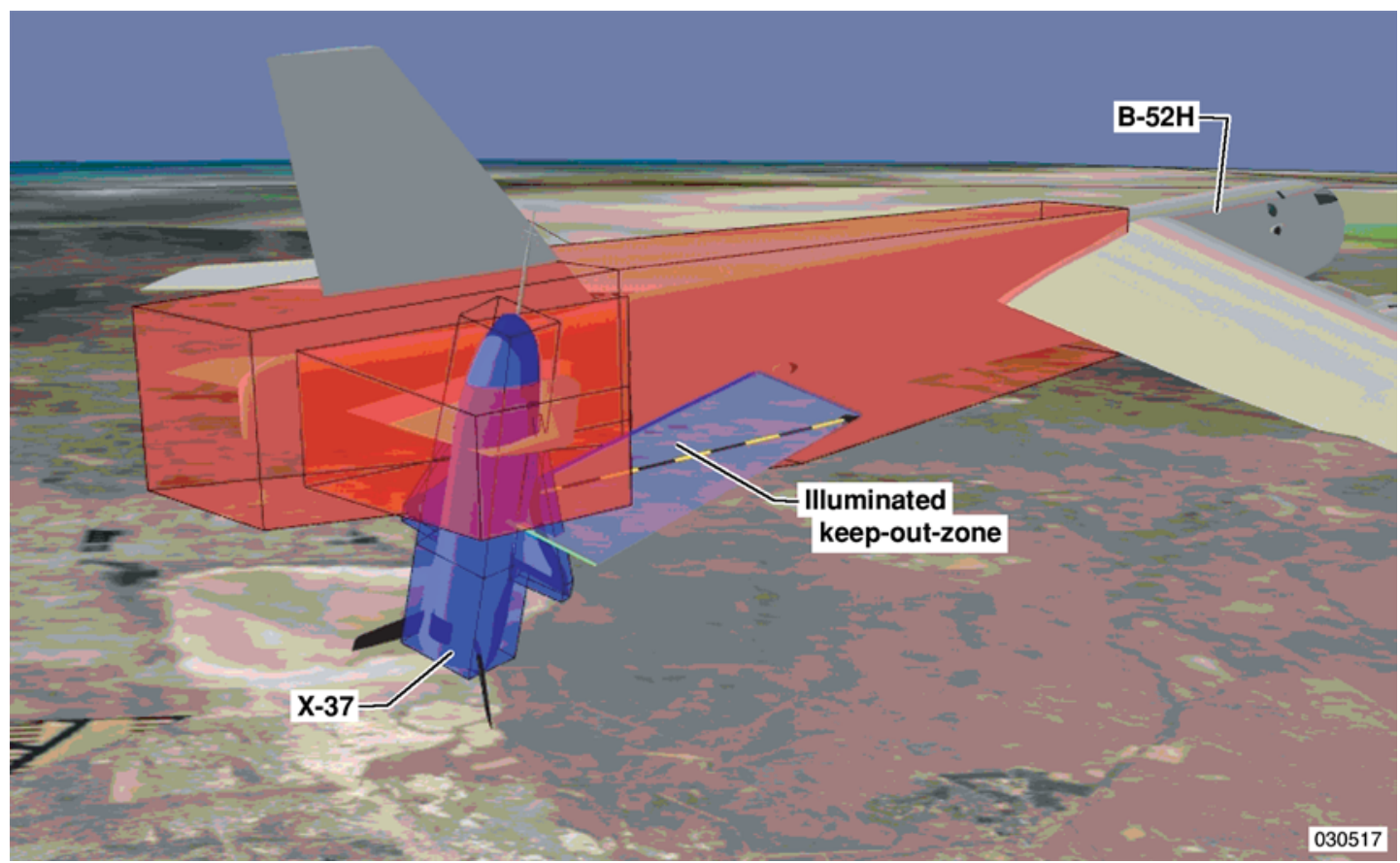

Figure 2. Simulation of the X-37 recontacting the B-52H tail area. 


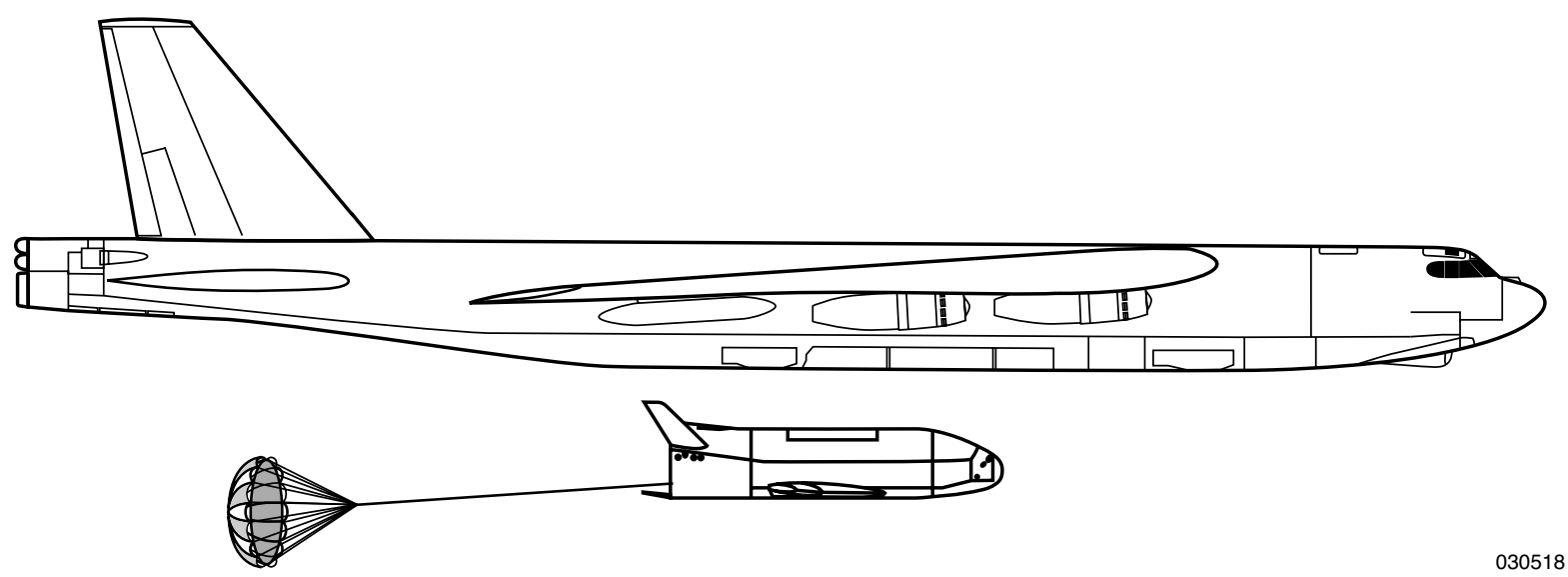

Figure 3. X-37 with drogue parachute soon after release from the B-52H carrier aircraft.

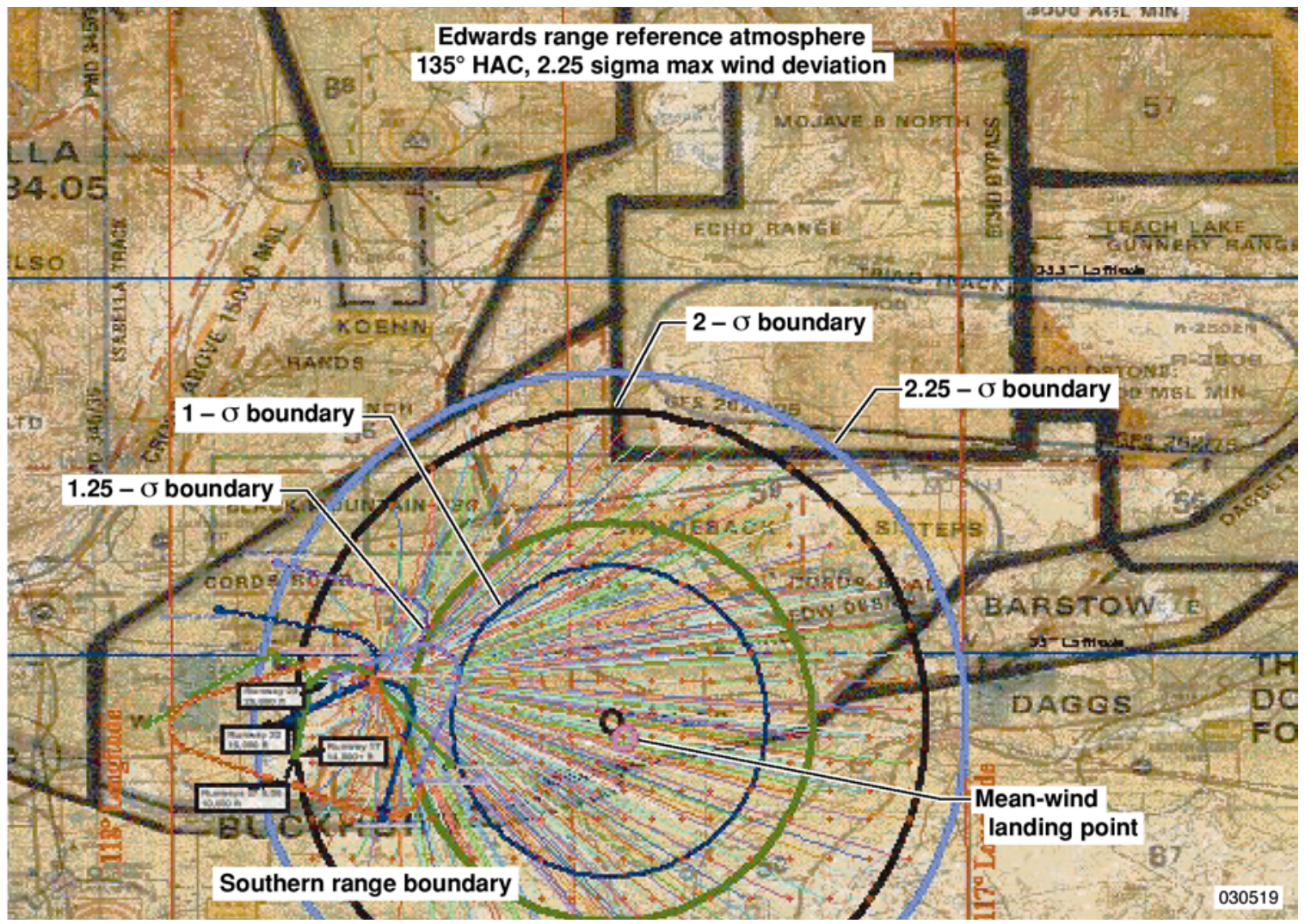

Figure 4. X-37 drogue parachute with full drag area, predicted post-release wind drift footprint. 


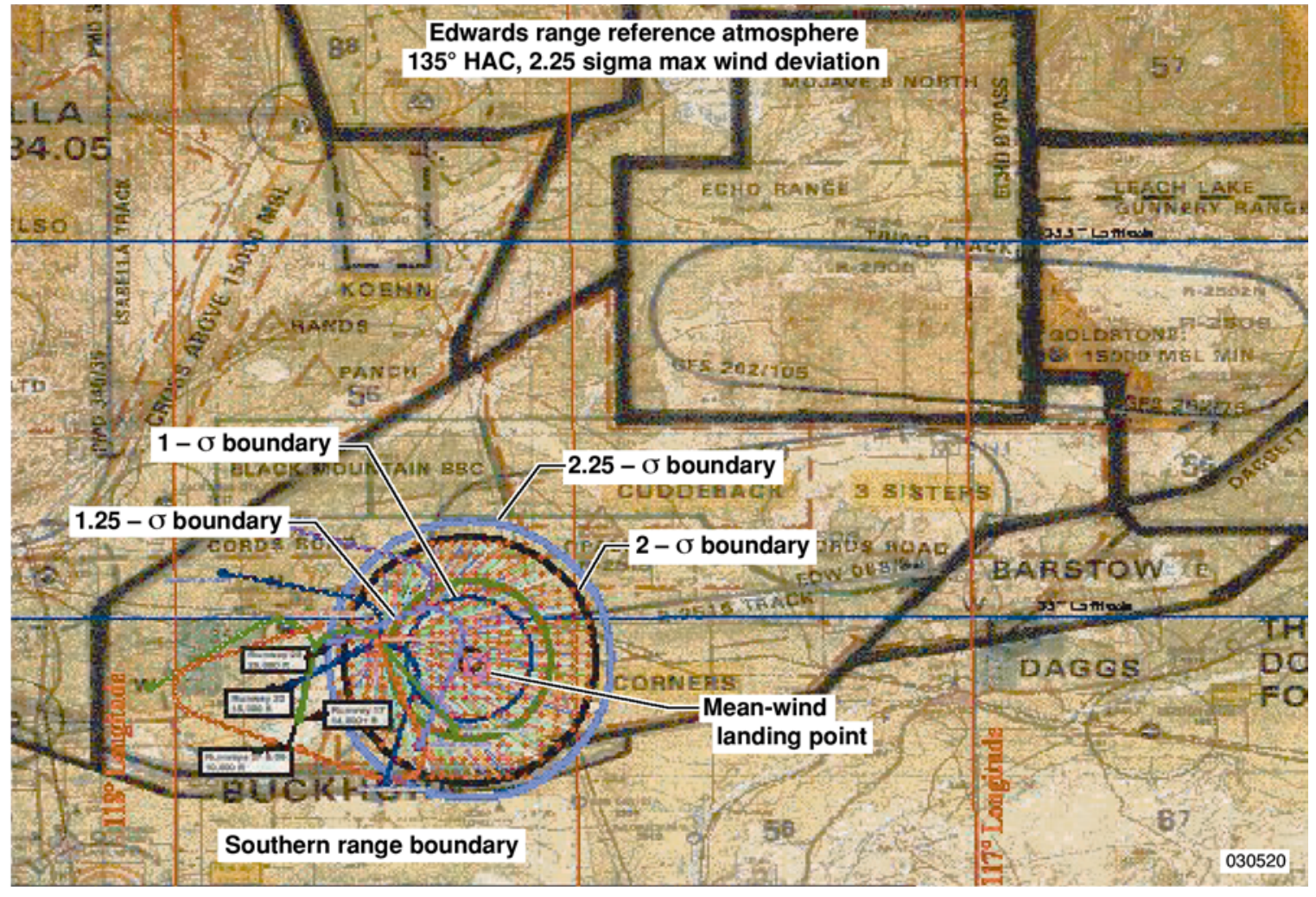

Figure 5. X-37 drogue parachute, predicted post-release wind drift footprint with 50 percent drag area reduction. 


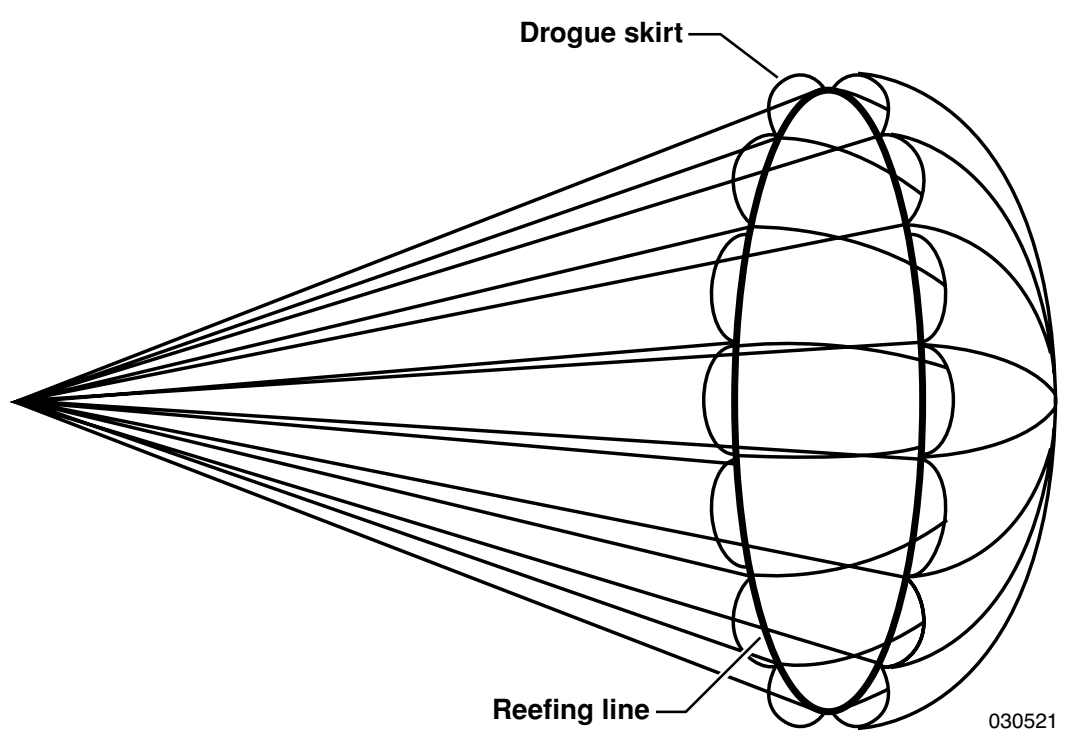

(a) Elastic reefing line in deployed condition.

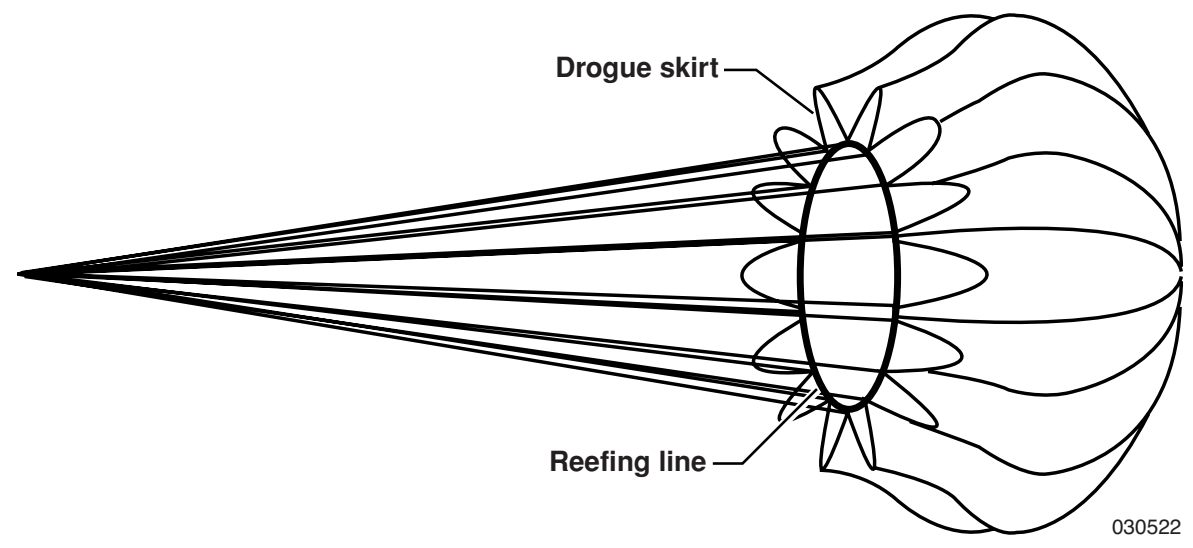

(b) Elastic reefing line in released condition.

Figure 6. Illustration of elastic reefing system concept. 


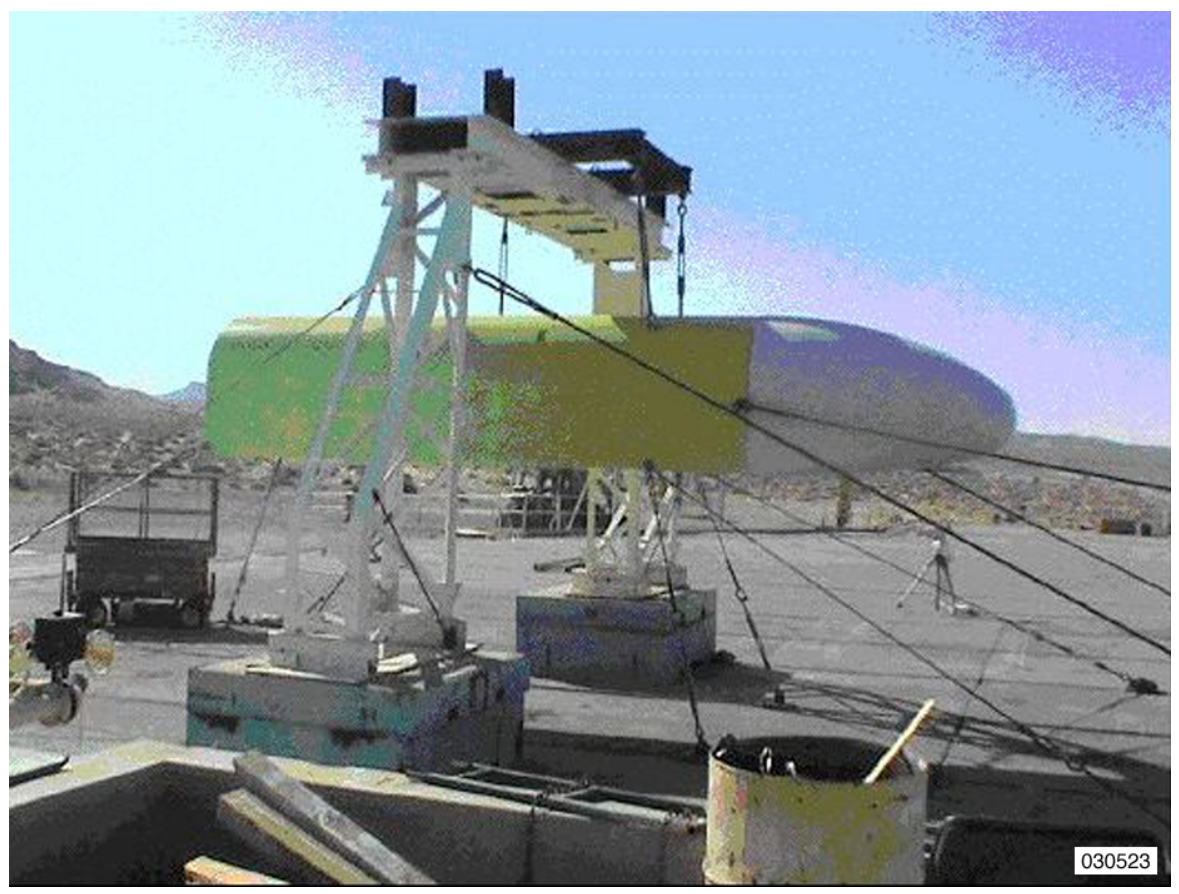

(a) Photograph of X-37 drogue parachute test fixture in HIVAS facility.

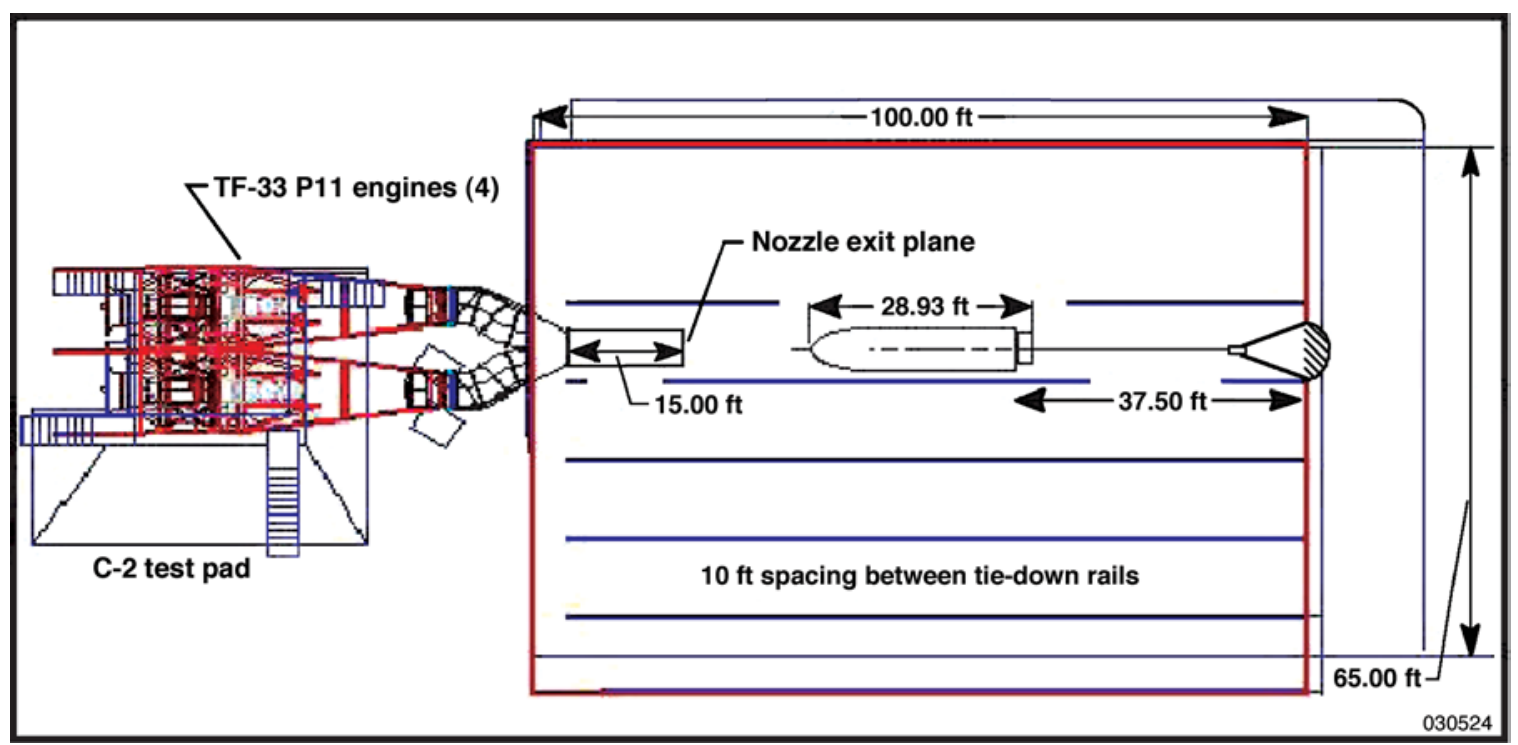

(b) Schematic of X-37 drogue parachute test fixture as mounted in HIVAS facility.

Figure 7. Drogue parachute test fixture mounted in HIVAS facility. 


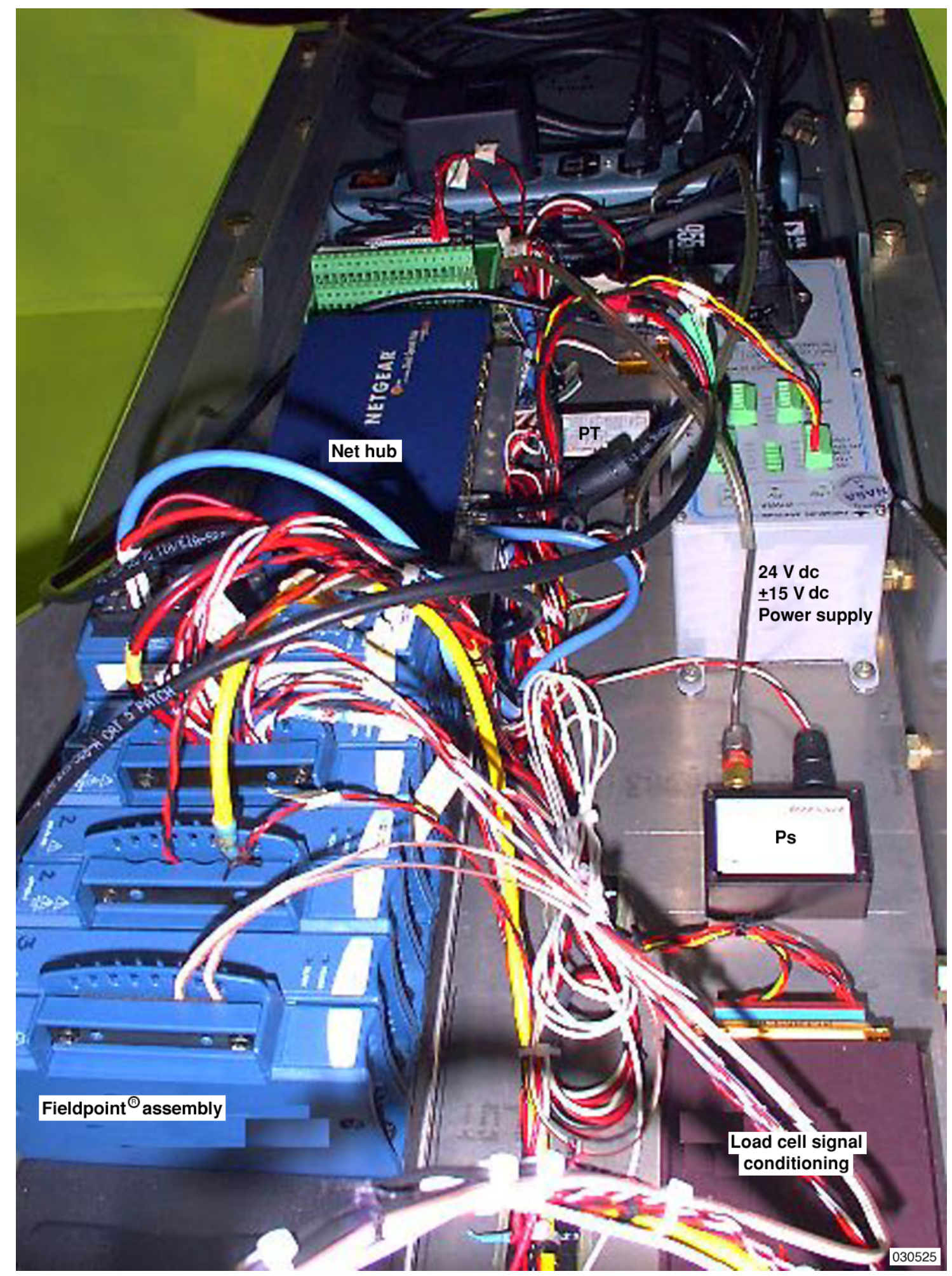

Figure 8. Fieldpoint ${ }^{\circledR}$ instrumentation assembly mounted to DCTF instrumentation pallet. 


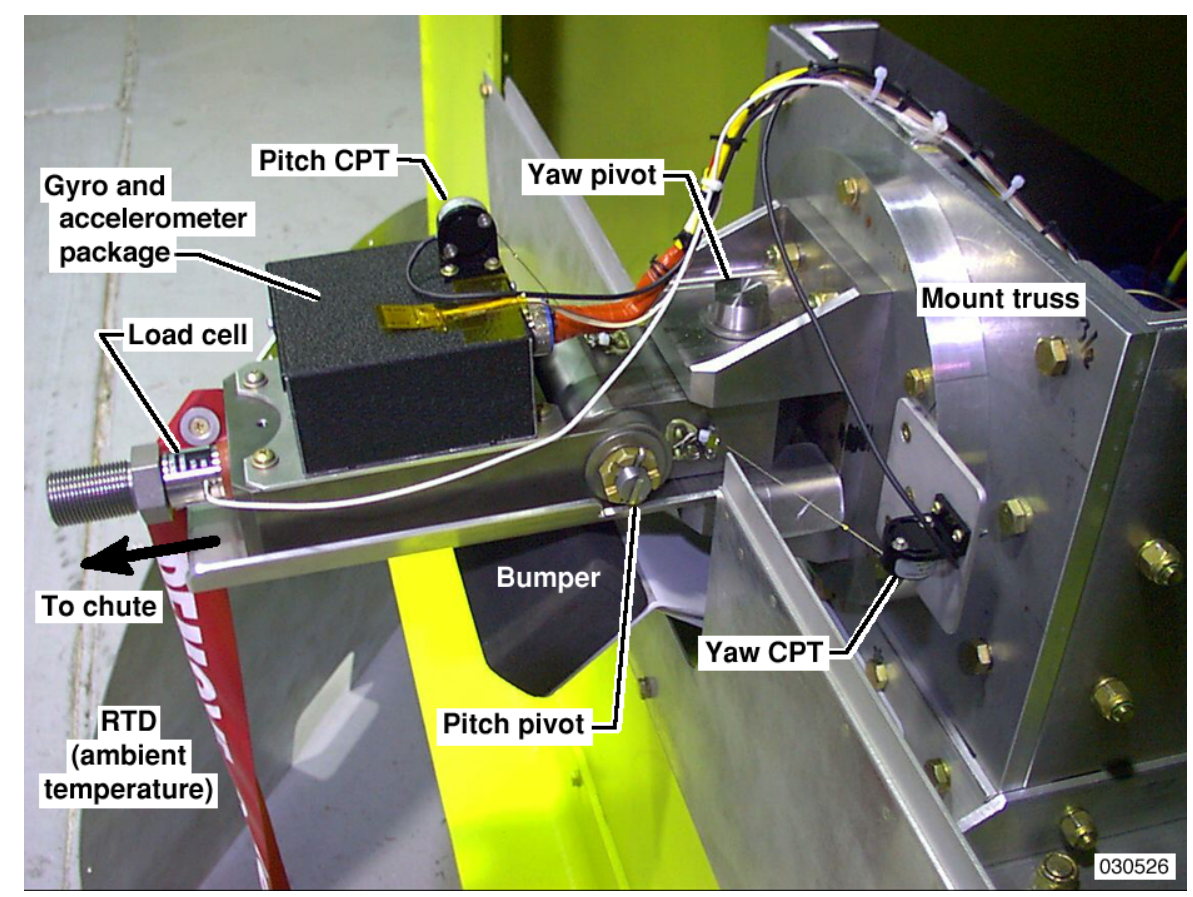

Figure 9. Three-DOF load balance and its mounting within aft end of text fixture.

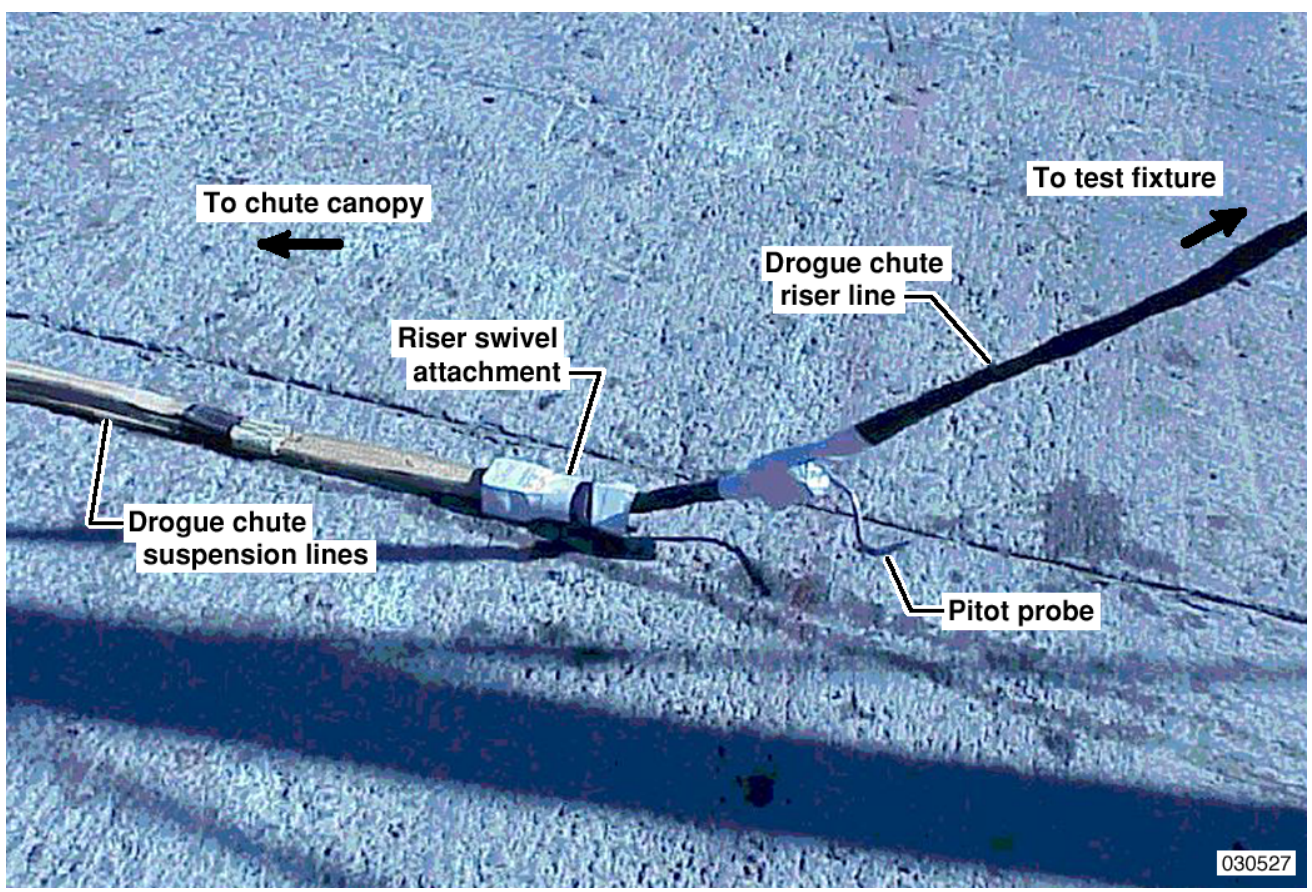

Figure 10. Pitot probe attached to parachute riser line. 


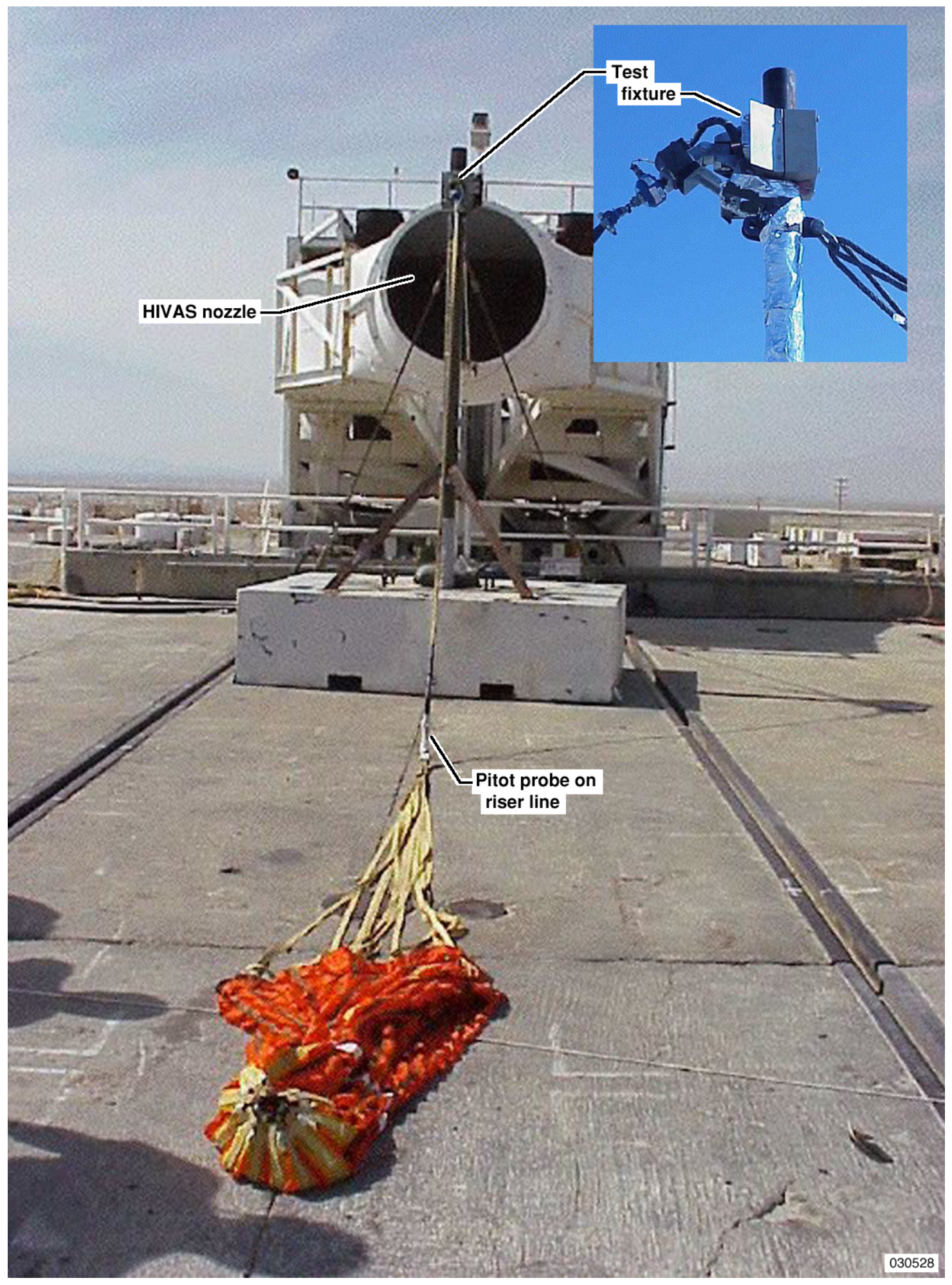

Figure 11. Parachute mounted to modified test fixture and ready for testing. 


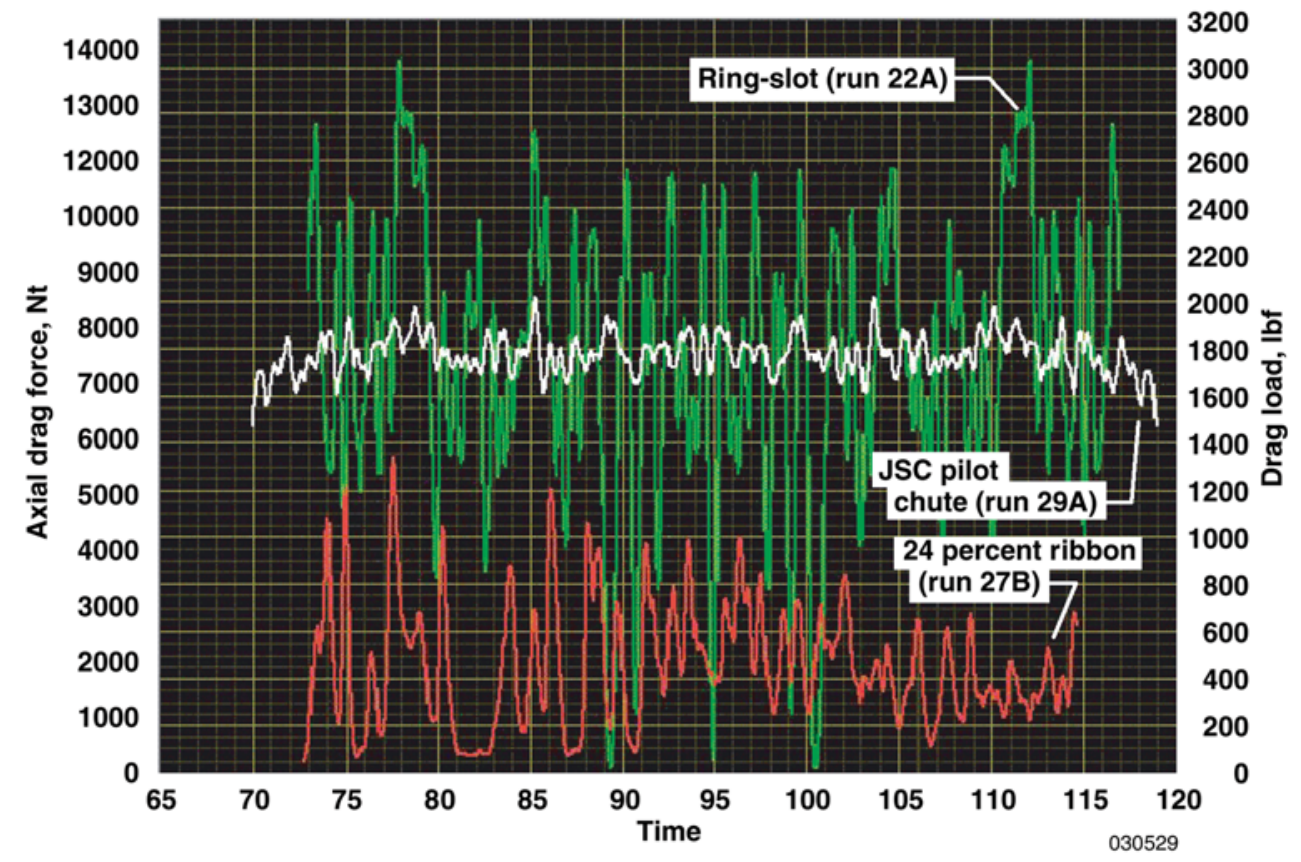

Figure 12. Side-by-side comparison of 24 percent ribbon, ring-slot, and Space Shuttle pilot parachute drag force as tested in HIVAS Phase II.

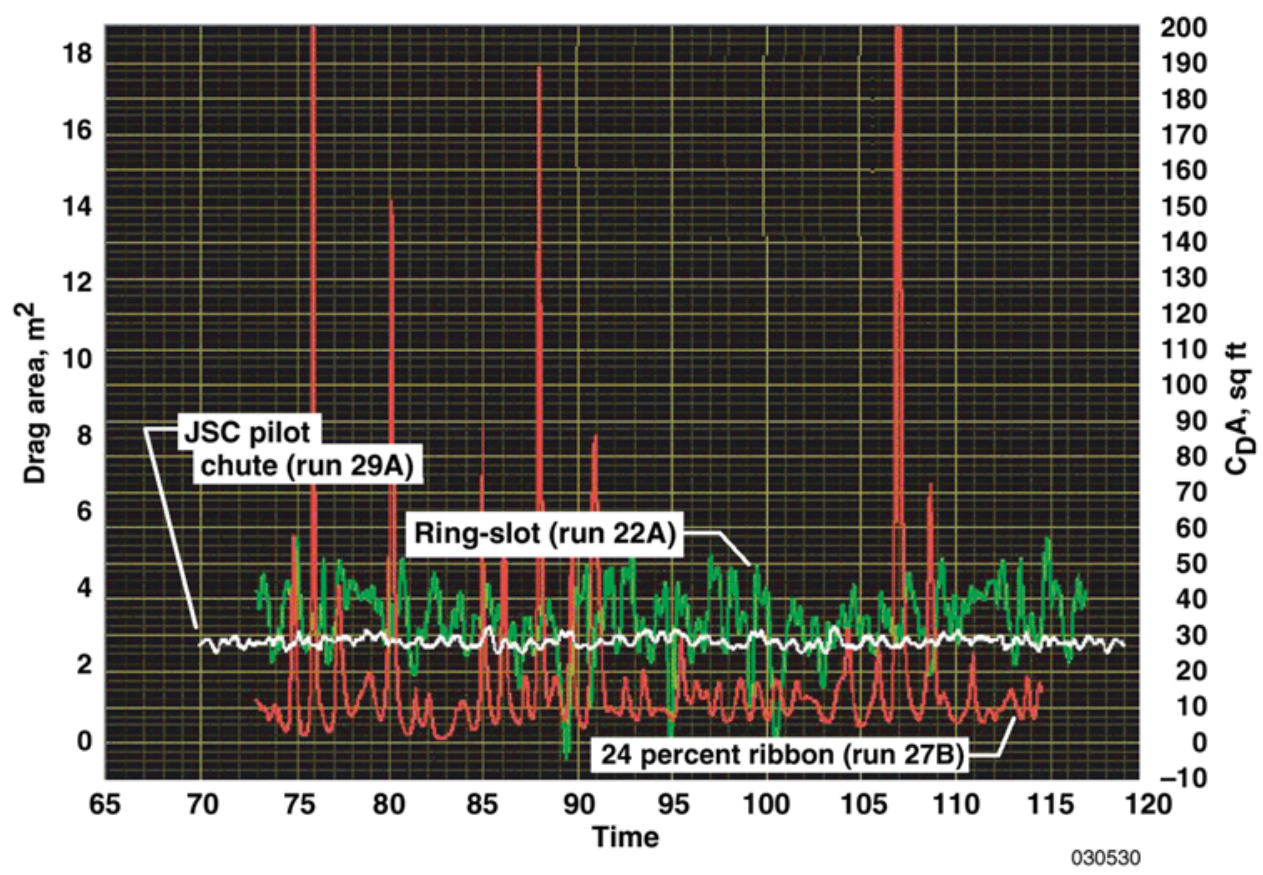

Figure 13. Side-by-side comparison of 24 percent ribbon, ring-slot, and Space Shuttle pilot parachute drag area as tested in HIVAS Phase II. 


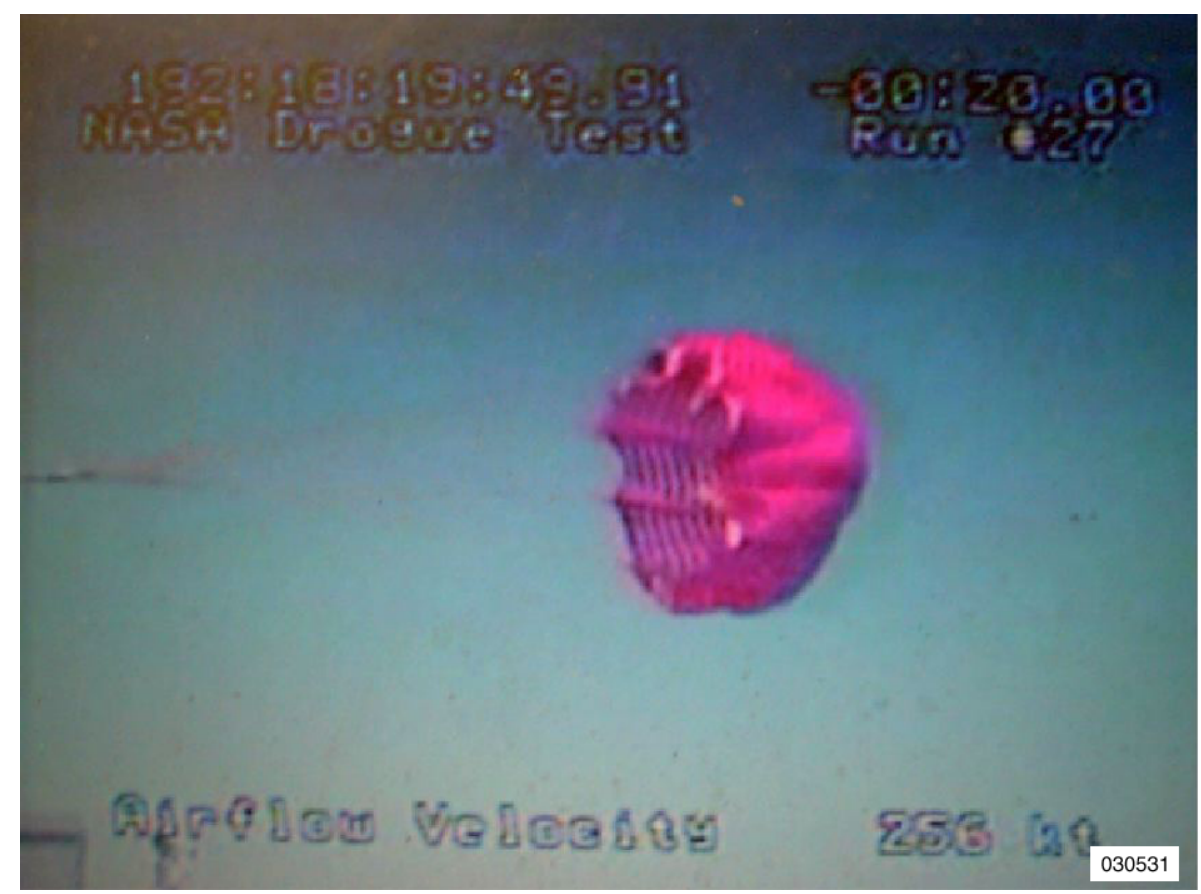

(a) Original 24 percent ribbon drogue parachute design.

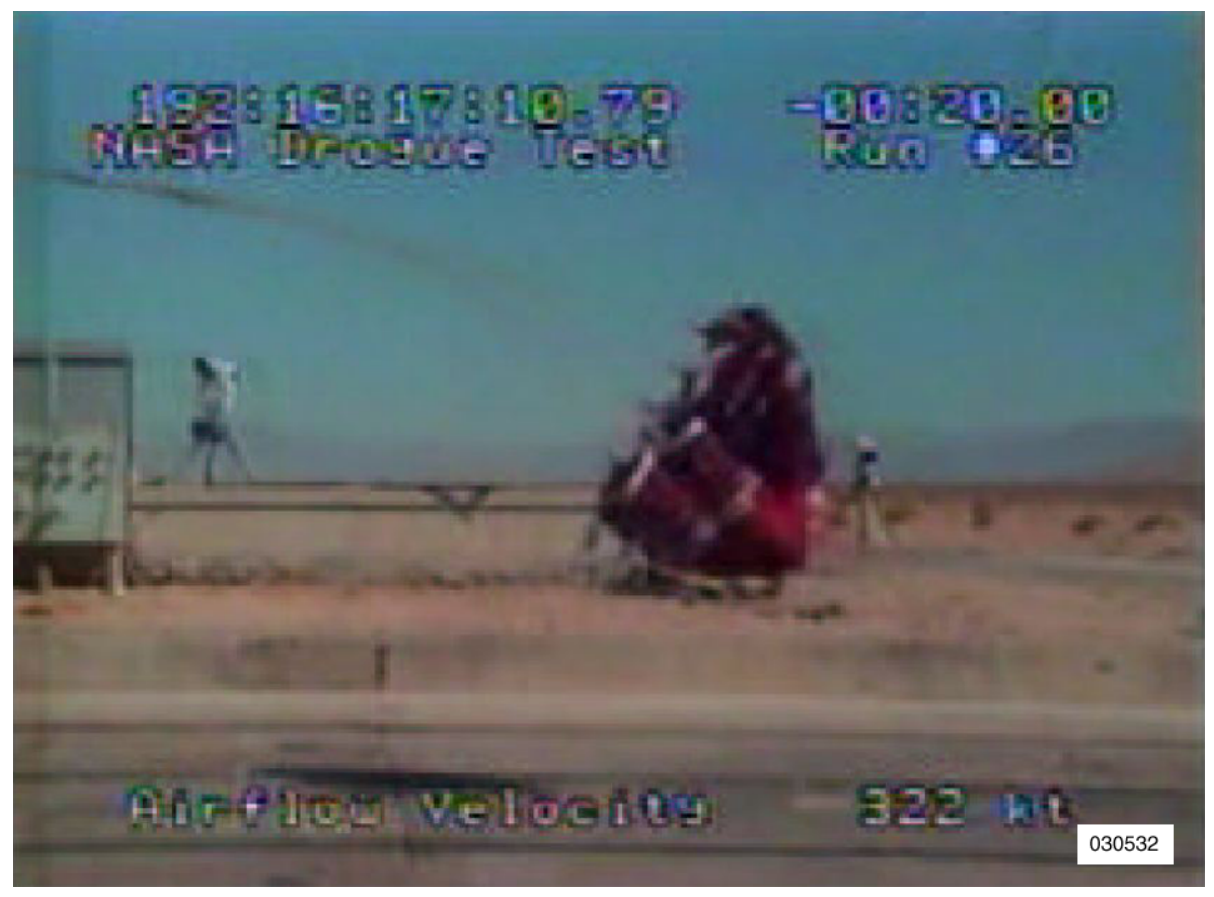

(b) Modified ring-slot drogue parachute design.

Figure 14. Visual comparison of inflation characteristics for three parachute designs tested in HIVAS phase II. 


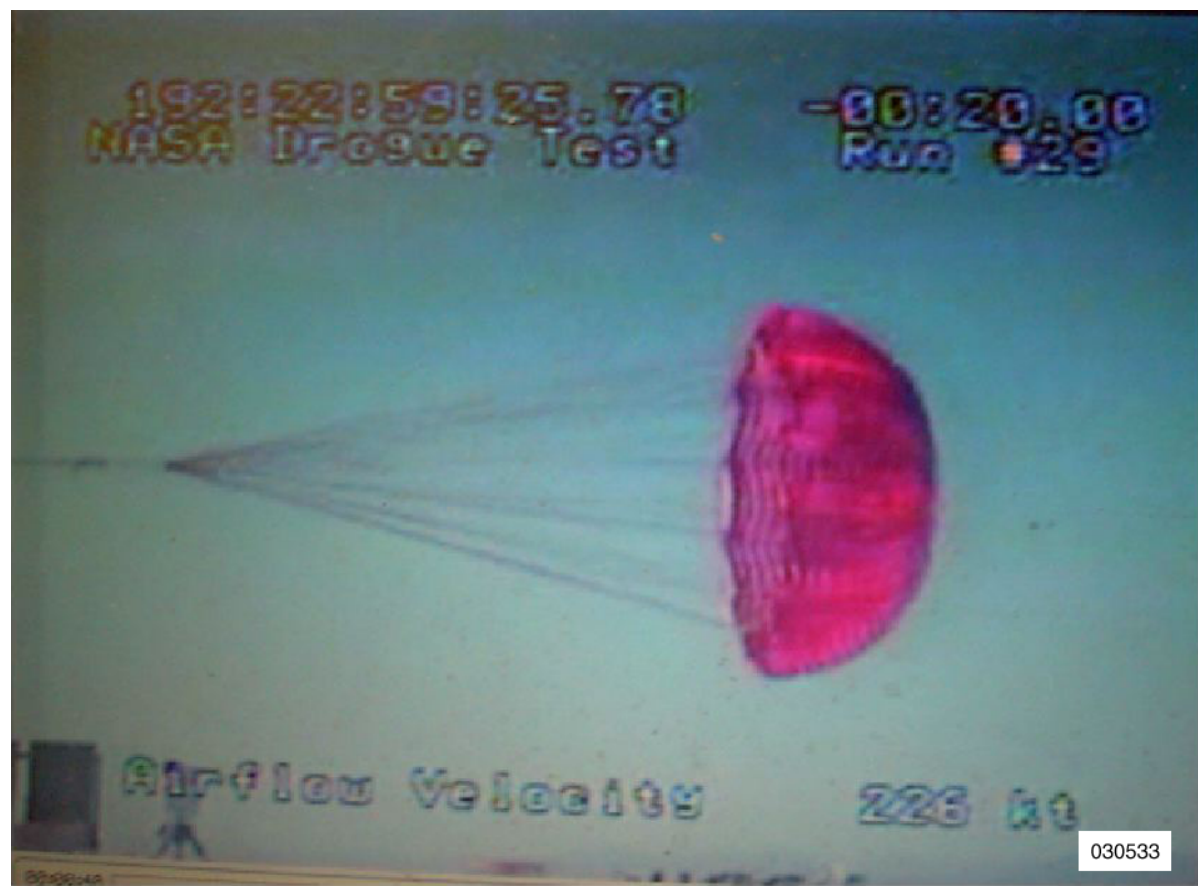

(c) JSC-Space Shuttle pilot parachute design.

Figure 14. Concluded.

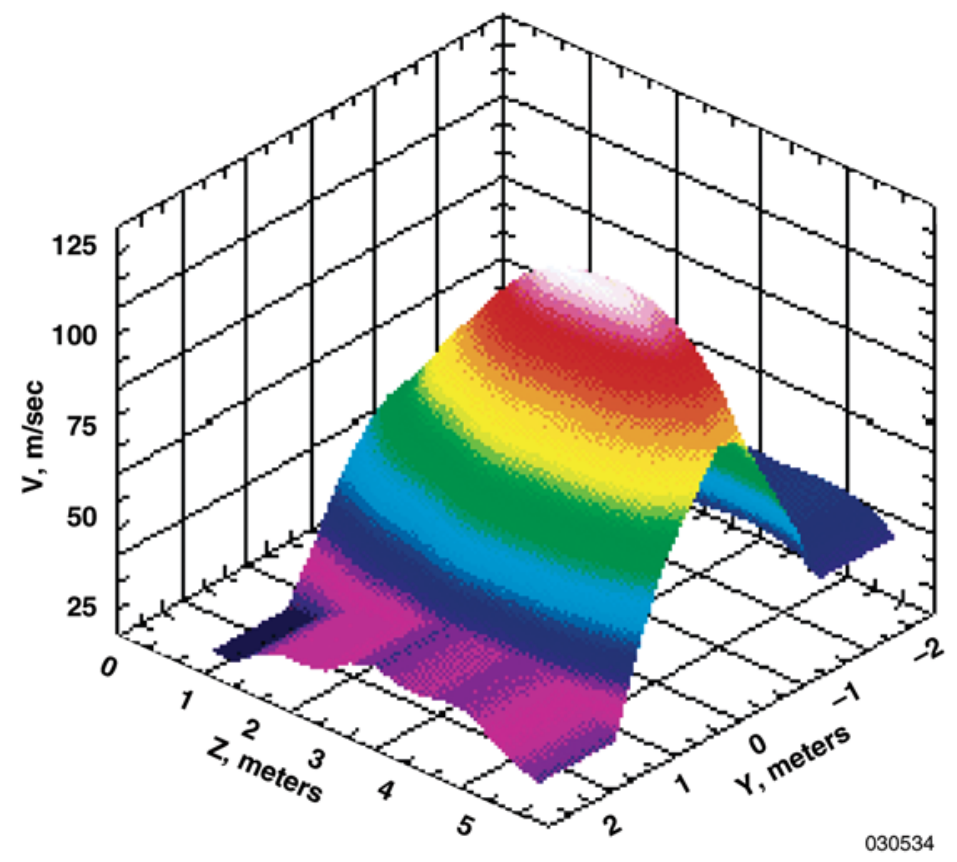

(a) Thirty meters aft of HIVAS nozzle without X-37 forebody model in flow field.

Figure 15. Effect of X-37 DCTF model on HIVAS flow field velocity distribution. 


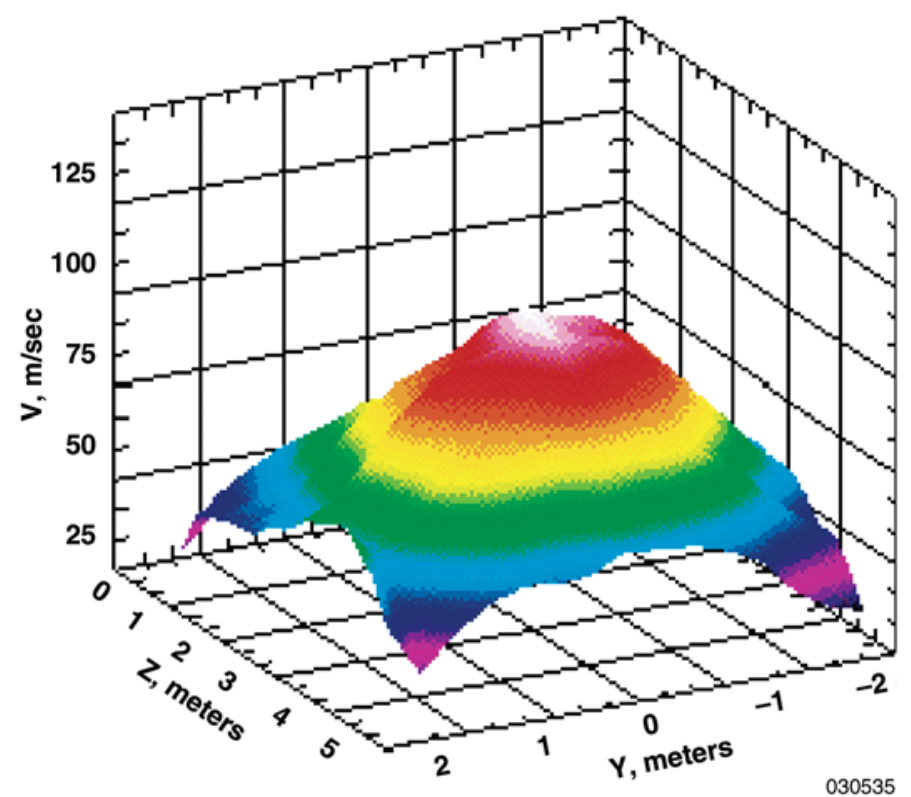

(b) Thirty meters aft of HIVAS nozzle with X-37 forebody model in flow field.

Figure 15. Concluded.

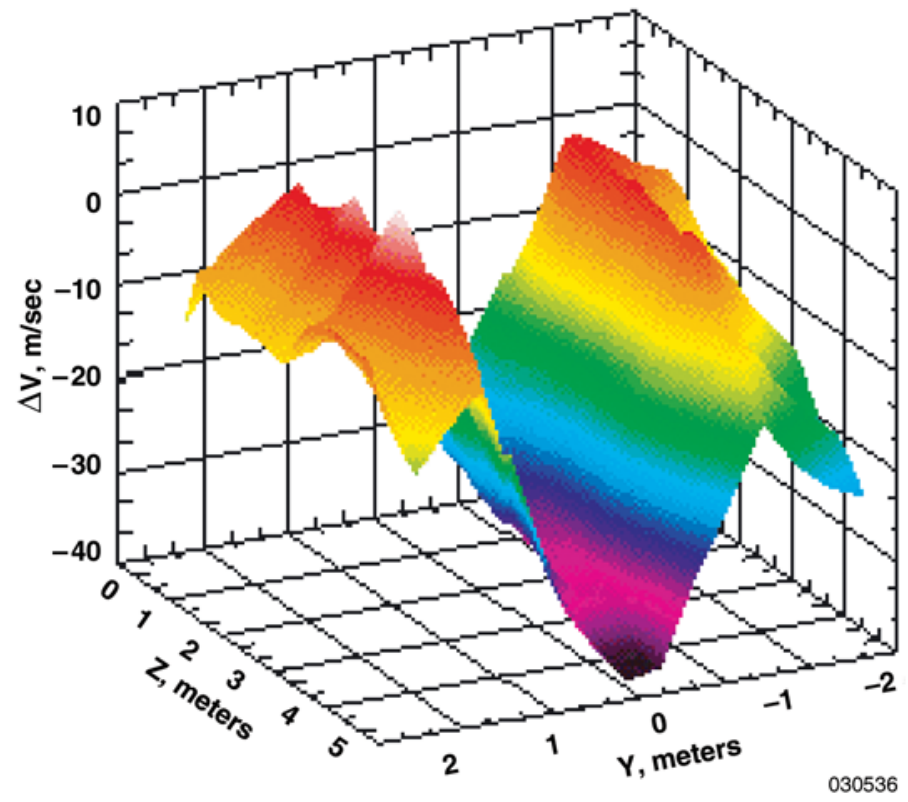

Figure 16. HIVAS flow field velocity defect caused by X-37 DCTF model. 


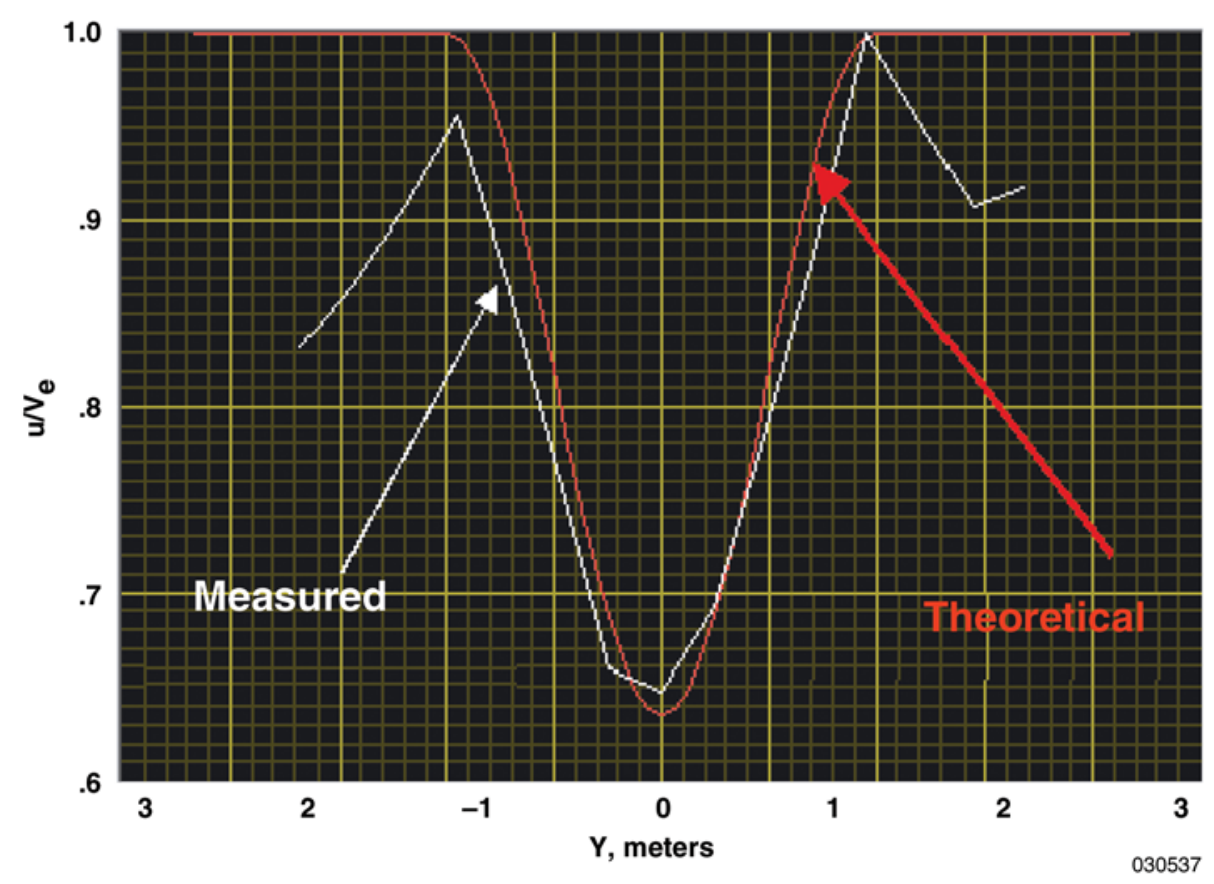

Figure 17. Comparison of measured and theoretical wake for X-37 DCTF model.

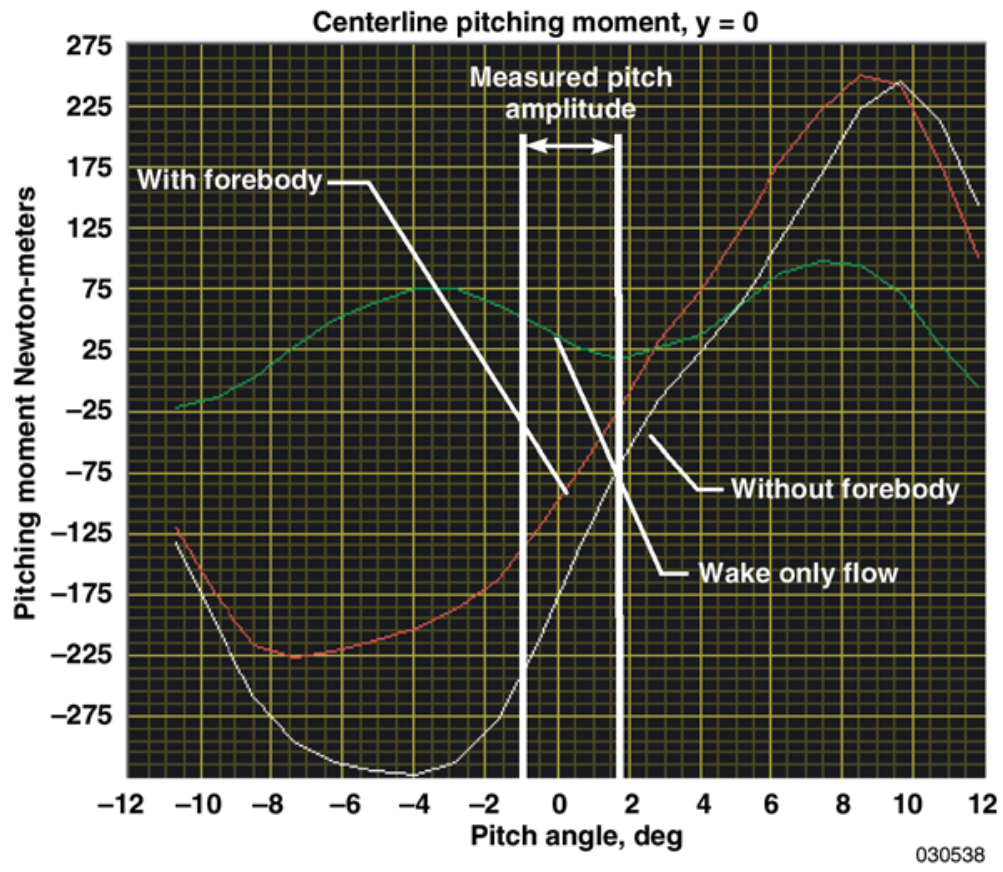

Figure 18. Effect of HIVAS velocity distribution on drogue parachute pitch axis stability. 


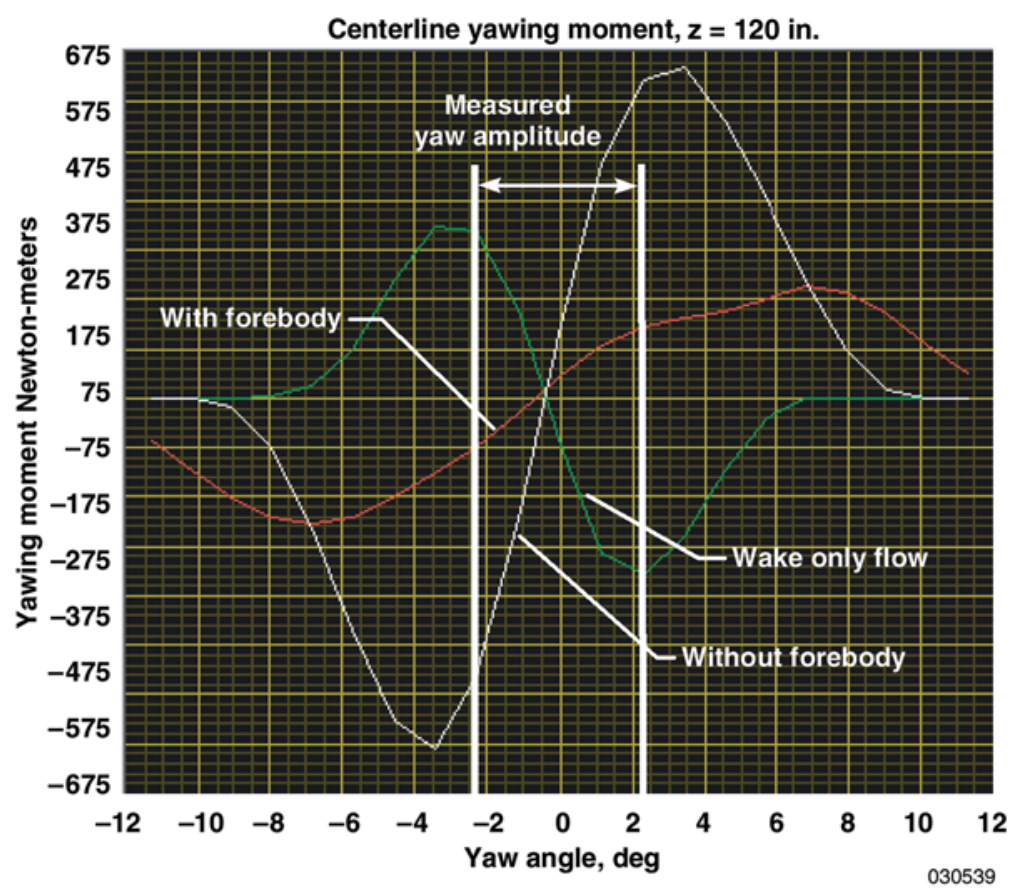

Figure 19. Effect of HIVAS velocity distribution on drogue parachute yaw axis stability.

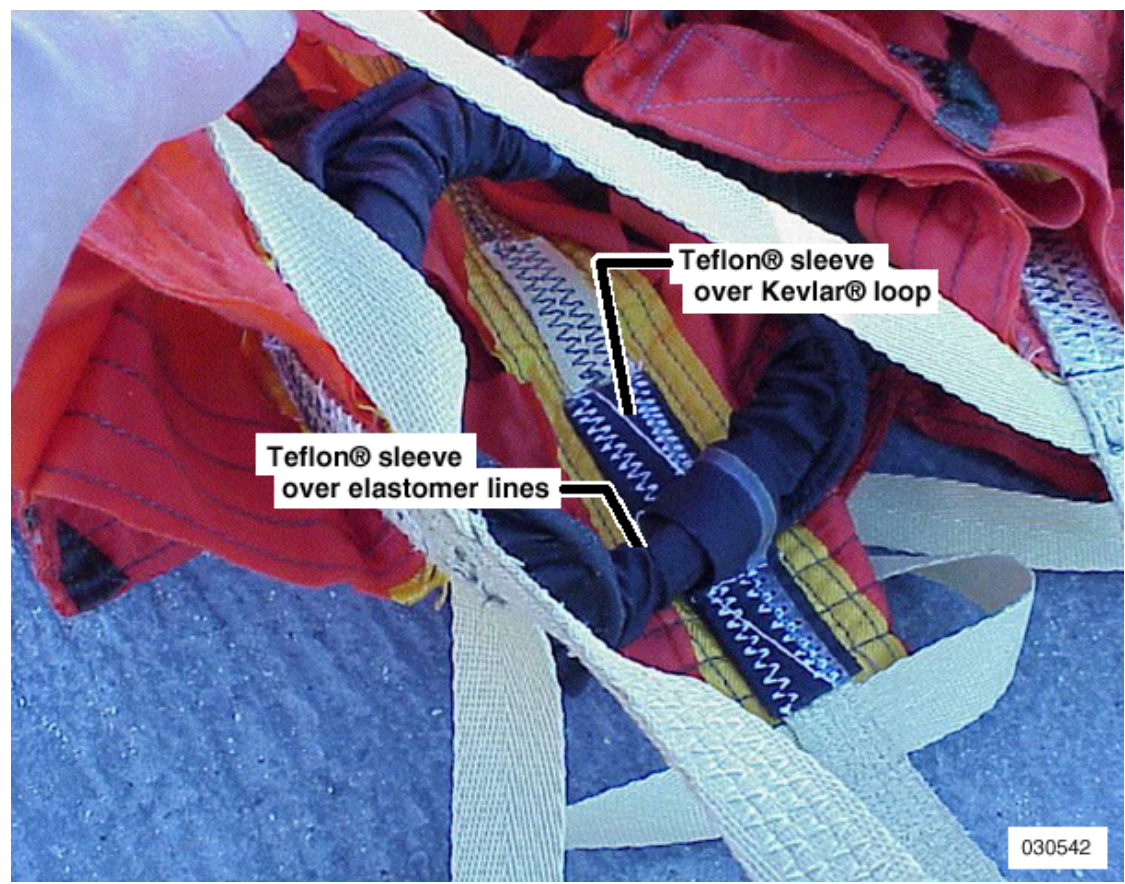

Figure 20. Elastomer reefing system attached to parachute skirt. 


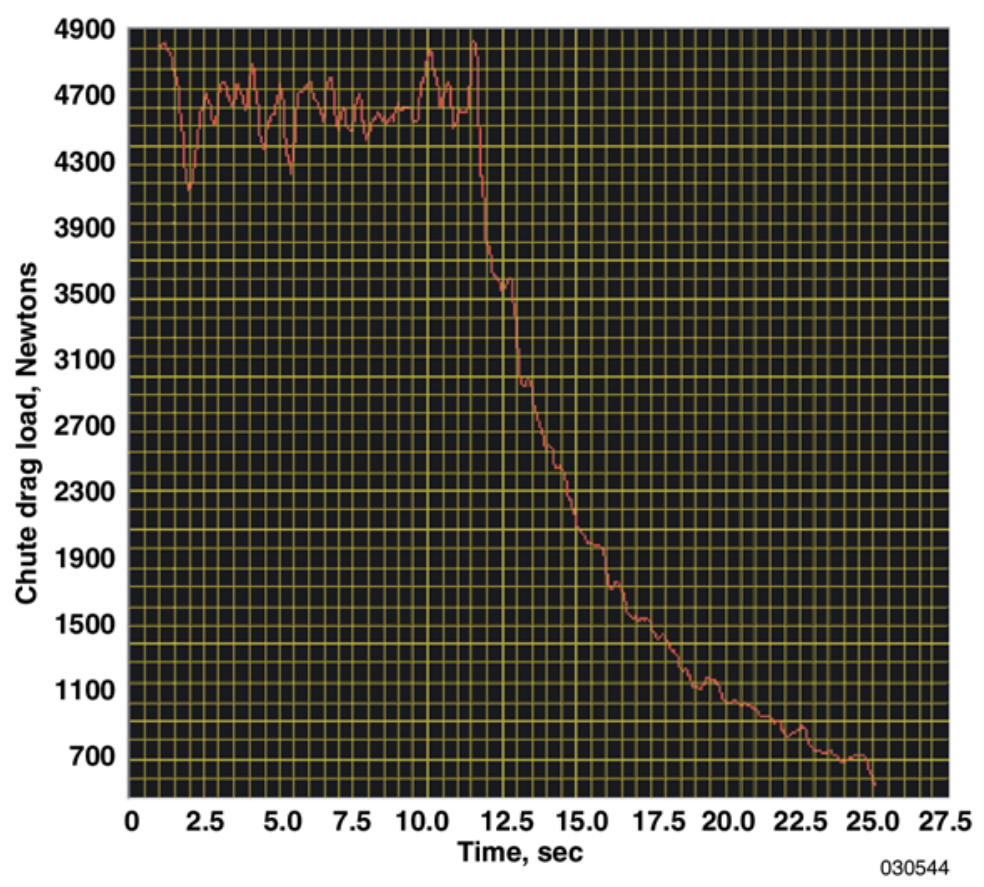

(a) Drag load.

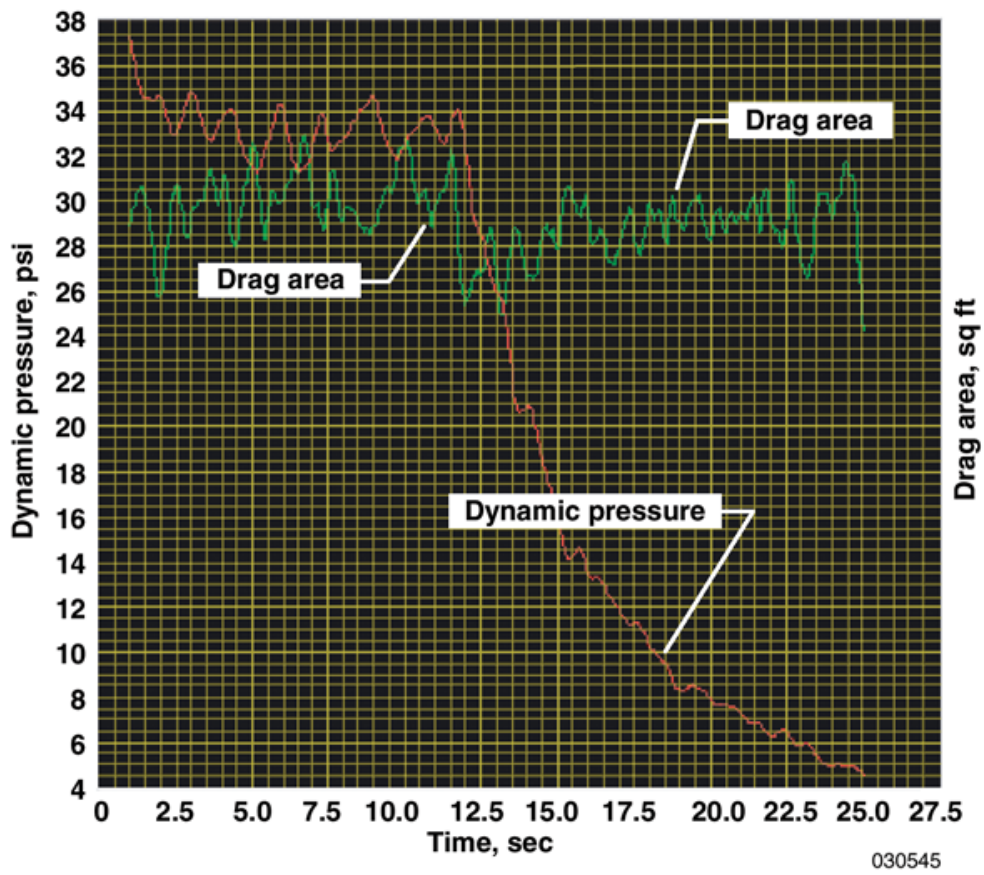

(b) Dynamic pressure and drag area.

Figure 21. Drogue parachute deflation cycle characteristics without elastomer reefing system. 


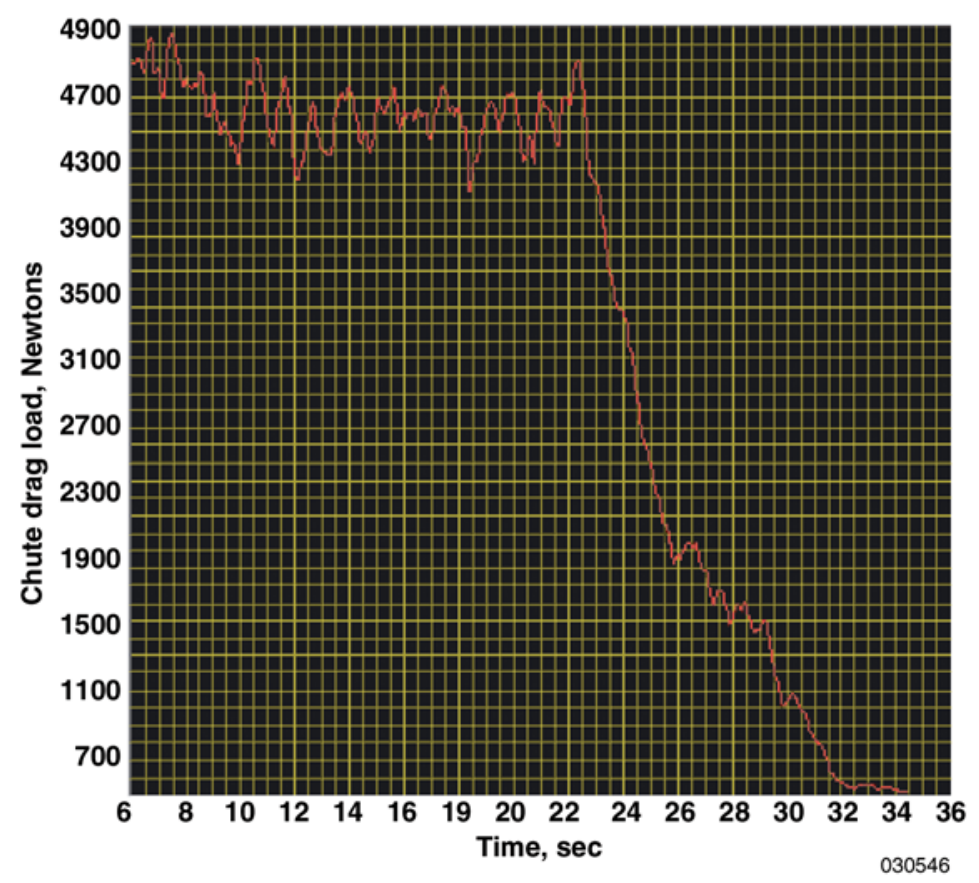

(a) Drag load.

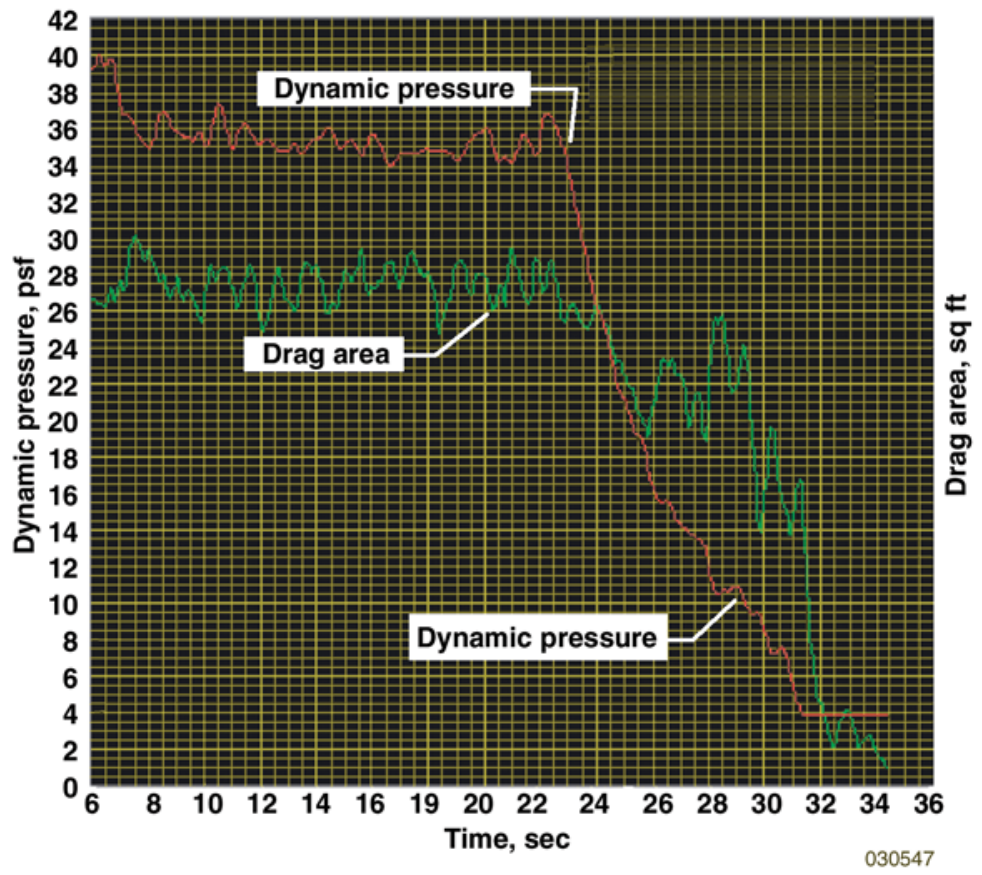

(b) Dynamic pressure and drag area.

Figure 22. Drogue parachute deflation cycle characteristics with elastomer reefing system. 